\title{
Moneda y espacios de poder en el reino visigodo. Los tremises de El Tolmo de Minateda (Hellín, Albacete) ${ }^{1}$
}

\author{
Coins and spaces of power in the Visigothic kingdom. The tremisses of El \\ Tolmo de Minateda (Hellín, Albacete)
}

\section{Carolina Doménech Belda*}

\begin{abstract}
RESUMEN
Los trabajos arqueológicos realizados en El Tolmo de Minateda (Hellín, Albacete) han permitido sacar a la luz los vestigios de una civitas visigoda creada a finales del siglo VI o inicios del VII. El material numismático recuperado en los niveles de uso y abandono de esta civitas está formado fundamentalmente por numerario de cobre de adscripción romana bajoimperial, y por tremises de oro de baja ley emitidos por el Estado visigodo. La contextualización estratigráfica y espacial de estas monedas ha permitido plantear diversas cuestiones referidas a la presencia y uso del numerario en época visigoda.
\end{abstract}

Palabras clave: Arqueología, Numismática, Tremís, Moneda bajoimperial romana, Estratigrafía, Alta Edad Media, Tolmo de Minateda, Reino Visigodo, Hispania.

\section{INTRODUCCIÓN}

Las monedas procedentes de excavaciones arqueológicas, tradicionalmente reducidas a meros indicadores cronológicos, aportan una información añadida a su potencial como informador histórico derivada de su localización en el marco de una secuencia estratigráfica. Dicha información en ocasiones es poco frecuente en los trabajos numismáticos, bien por ser escasa o inexistente, sobre

\begin{abstract}
The archaeological fieldwork carried out in El Tolmo de Minateda (Hellín, Albacete) has made possible to recover the traces of a Visigothic town erected at the end of the $6^{\text {th }}$ century or in the beginning of the $7^{\text {th }}$ century. The numismatic material recovered on levels of use and abandonment in this town is mainly composed by copper coinage from later Roman Empire, and by golden tremisses of lowgrade metal coined by the Visigothic kingdom. The stratigraphical contexts of this coins have allowed to raise some questions about the presence and use of the numerary in the Visigothic period.
\end{abstract}

Keywords: Archaeology, Numismatic, Tremissis, Late roman coins, Stratigraphy, High Middle Age, Tolmo de Minateda, Visigothic kingdom, Hispania.

todo cuando se trata de hallazgos antiguos, bien por la ausencia de interacción entre el arqueólogo que realiza el trabajo de campo y el numismático que estudia los materiales monetarios. Esta circunstancia tiene como resultado la pérdida de unos datos de gran valor histórico que, muchas veces, resultan primordiales para avanzar en algunas problemáticas que se presentan estancadas o irresolubles. La información obtenida con la contextualización estratigráfica de los regis-

\footnotetext{
* Universidad de Alicante

1 Este trabajo ha sido realizado en el marco del proyecto de investigación HAR2012-34035 Lectura arqueológica del uso social del espacio. Espacios domésticos y vida social entre la Antigüedad y el Medievo del Ministerio de Economía y Competitividad. Queremos agradecer la colaboración del equipo que trabaja en este proyecto, sin la cual no hubiera sido posible realizar este estudio y, en especial, a Sonia Gutiérrez Lloret por compartir sus reflexiones y a quien este texto debe mucho. Los errores que pueda contener son solo míos.
} 
tros numismáticos resulta fundamental y, en muchos casos, es el único camino a la hora de abordar cuestiones tan importantes como son la detección de fenómenos de pervivencia de numerario, la cuantificación espacial y temporal de esa perduración, el conocer los usos de algunas especies monetarias, establecer su atribución a un determinado poder emisor, así como su adscripción cultural o su momento de uso ${ }^{2}$.

Para el numerario visigodo, el estudio de los contextos se revela como una importante herramienta capaz de aportar nuevos datos a una vieja problemática: la de determinar el uso de la moneda de oro en la sociedad visigoda. Las emisiones áureas hechas por el Estado visigodo han sido muy discutidas en cuanto a su uso y función debido a que una moneda de alto valor intrínseco como el tremís no parece, en principio, la más adecuada para ser utilizada como elemento de intercambio, más allá de los ámbitos vinculados con los grupos de poder. La ausencia de acuñaciones en otros metales menos valiosos, que deja al tremís como la única moneda acuñada por el reino visigodo a partir de Leovigildo, incide claramente en esta cuestión. Por ello, los hallazgos numismáticos vinculados a contextos arqueológicos conocidos, aunque todavía escasos, revisten gran interés, ya que permiten conocer el carácter de los espacios en que las monedas fueron depositadas o perdidas y, por tanto, usadas, estableciendo ámbitos de circulación que ayudan a concretar su función ${ }^{3}$, toda vez que su relación con otros materiales aporta información sobre su pervivencia o cotidianeidad con otros numerarios.
En este sentido, el estudio del material numismático recuperado en el transcurso de las excavaciones arqueológicas regulares y sistemáticas que se vienen realizando en $\mathrm{El}$ Tolmo de Minateda en Hellín (Albacete) ${ }^{4}$, ha permitido conocer el numerario que circulaba en esta civitas visigoda que, como sucede en otras ciudades coetáneas, no es solamente el acuñado por el Estado visigodo, sino que comprende emisiones más antiguas, con un claro predominio del numerario de cobre tardorromano. Sin perder de vista esta realidad, el presente trabajo pretende dar a conocer el numerario de factura visigoda recuperado en el yacimiento y la realidad espacial y estratigráfica donde se sitúa.

\section{LA CIUDAD VISIGODA DE EL TOLMO DE MINATEDA}

El yacimiento arqueológico de El Tolmo de Minateda se encuentra en un cerro amesetado que ocupa una privilegiada posición estratégica y domina la vía natural que comunica las tierras del interior de la Península con la región costera del sudeste (Figura 1). Dicha vía está documentada como calzada al menos desde época romana mediante miliarios (SILLIĖRES, 1982 y 1990), y se ha mantenido en uso hasta la actualidad. El asentamiento domina el punto donde este eje que unía Complutum con Carthago Noua, se cruzaba con la vía trasversal que desde Valencia llegaba hasta la Alta Andalucía (ABAD, GUTIÉRREZ Y SANZ, 1998).

La ubicación del enclave y su morfología han favorecido una larga ocupación del

2 En este sentido, el Congreso Nacional de Numismática celebrado en Cádiz en el año 2007 bajo el lema "Numismática y Arqueología" puso en evidencia el cambio producido en algunos sectores del campo de los estudios numismáticos que, revalorizando el potencial de la moneda de excavación, abogaban por una disciplina en la que los registros numismáticos y los contextos arqueológicos en los que aparecen se interrelacionan estrechamente, de manera que la moneda adquiere así todo su valor como documento histórico. Véase C. Doménech, 2009.

3 Véanse los trabajos de M. Castro (2010 y 2011) quien, a partir de los hallazgos y sus contextos arqueológicos establece diversos patrones organizativos y de producción que permiten distinguir modelos y circuitos regionales; y los de I. Martín Viso sobre fiscalidad visigoda basados, en parte, en los hallazgos de moneda visigoda, los talleres de emisión y el volumen de piezas conocidas (MARTÍN VISO, 2006, 2008 a y b, 2011 y 2013).

4 Dichos trabajos arqueológicos dieron comienzo en el marco de un proyecto autorizado y financiado por la Dirección General de Educación, Ciencia y Cultura, de la Junta de Comunidades de Castilla-La Mancha, en el que participan la Universidad de Alicante y el Museo de Albacete. En 2012 el yacimiento fue declarado Parque Arqueológico de la Provincia de Albacete (ABAD et alii 2012) según decreto 81/2012, de 26/04/2012, de declaración del Parque Arqueológico del Tolmo de Minateda en Hellín (Albacete) [2012/6577]. 


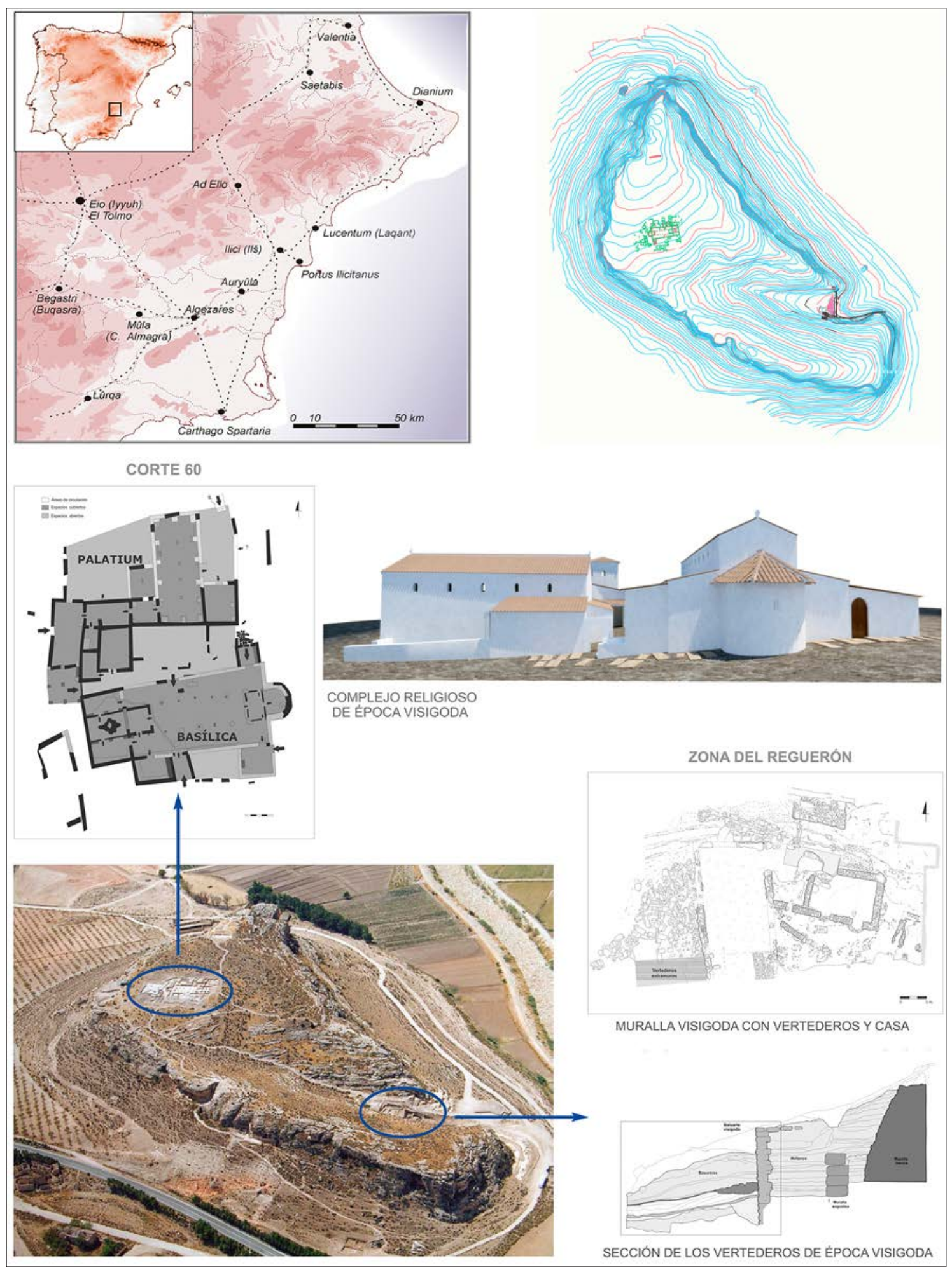

Fig. 1. Vista y ubicación de El Tolmo de Minateda con planimetría general del enclave.

asentamiento. La secuencia habitacional se remonta a la Edad del Bronce y se prolonga en el tiempo con periodos de abandono hasta alcanzar la época contemporánea. Fue un oppidum ibérico convertido en municipio romano a principios del Imperio con el nombre de Ilunum (ABAD, 1996). En el siglo II d.C. la ciudad entró en un proceso de declive que cul- 
minaría con su abandono a lo largo de la centuria, a la vez que se documentan una serie de asentamientos que hacen su aparición en el llano circundante. El cerro permaneció inhabitado algunas centurias hasta que volvió a ser ocupado a finales del siglo VI o inicios del VII en el marco del conflicto grecogótico. Esta reocupación generó una importante actividad constructiva y su reviviscencia como ciudad.

El asentamiento de época visigoda fue construido ex novo sobre la antigua ciudad romana prácticamente abandonada en época imperial ${ }^{5}$. El programa constructivo consistió en la fortificación del principal acceso a la ciudad, la ocupación urbana del cerro y la erección de una gran área monumental en la parte alta de la ciudad formada por una basílica de tres naves con baptisterio, un cementerio ad sanctos y un gran edificio identificado como el palacio episcopal (Figura 2). Este complejo arquitectónico fue concebido de manera unitaria y construido ignorando posibles restos constructivos anteriores, alterando la topografía del lugar al recortar parte de la roca con el fin de obtener un gran espacio que pudiera acoger a ambos edificios. Sus dimensiones y su ubicación en un lugar central en la meseta del cerro lo harían visible desde cualquier punto de la civitas $^{6}$.

La basílica es un edificio de tres naves con ábside semicircular exento, y un baptisterio a los pies conformado por tres estancias e integrado en la misma unidad constructiva ${ }^{7}$. El palatium, de estruc-

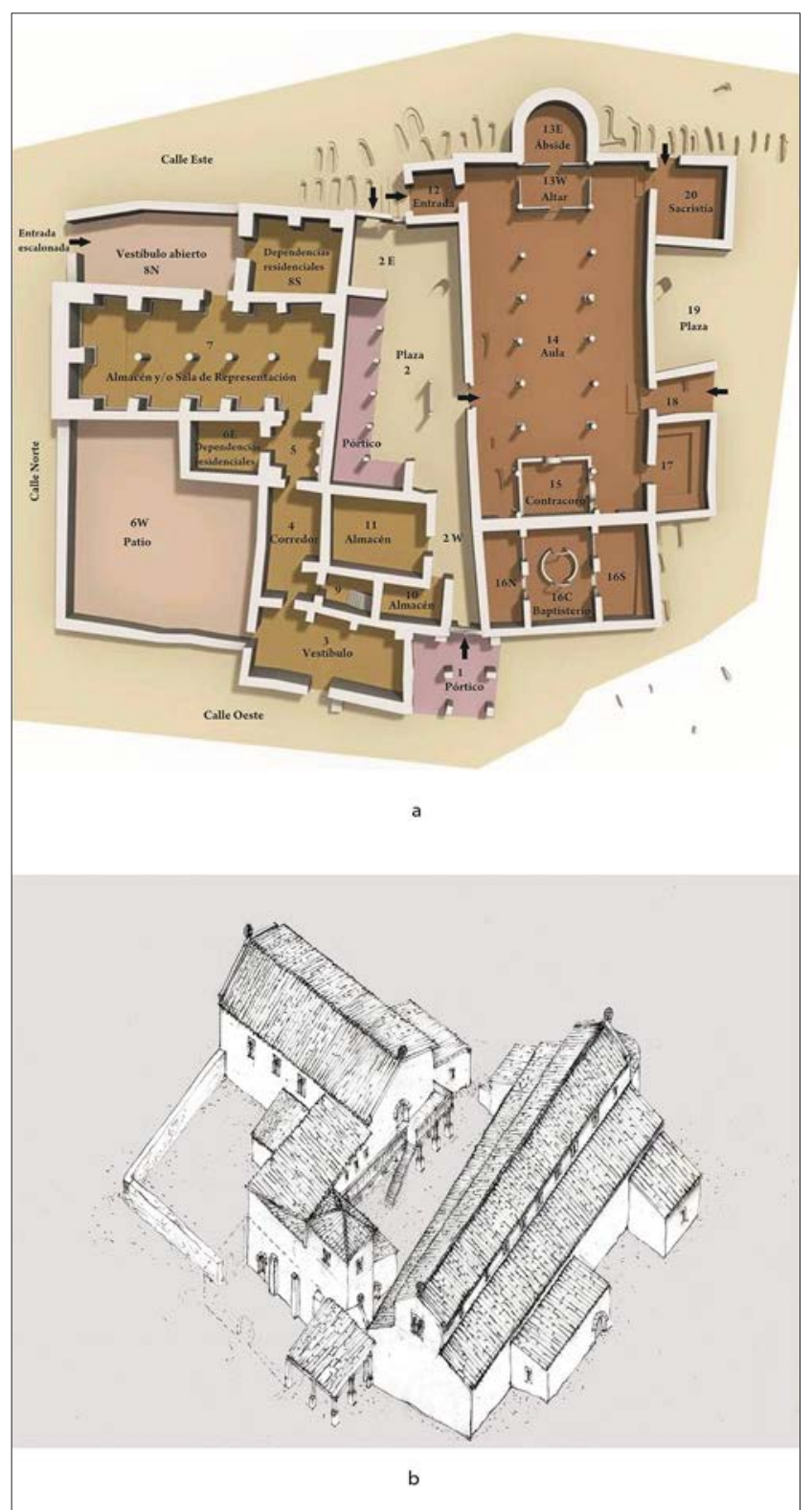

Fig. 2. A: Planta del complejo monumental visigodo (C) Parque Arqueológico Tolmo de Minateda). B: Perspectiva axonométrica con una propuesta de reconstrucción (dibujo D. Kiss), según Gutiérrez y Sarabia, 2013.

tura más compleja, se encuentra situado al norte de la basílica en paralelo al eje mayor

5 La civitas visigoda de El Tolmo de Minateda cuenta ya con una amplia bibliografía entre la que merece destacarse para el tema que nos ocupa L. Abad y S. Gutiérrez, 1997; L. Abad, S. Gutiérrez y B. Gamo, 2000 a; L. Abad, S. Gutiérrez, B. Gamo y P. Cánovas, 2008; V. Amorós, 2012; V. Amorós, V. Cañavate, S. Gutiérrez y J. Sarabia, 2012; B. Gamo, 1998; S. Gutiérrez Lloret, 1999,2000 a, b y c, 2008, 2011; S. Gutiérrez y L. Abad, 2002; S. Gutiérrez, L. Abad y B. Gamo, 2004, 2005; S. Gutiérrez y I. Grau, 2012; S. Gutiérrez y J. Sarabia, 2007, 2013 y (en prensa).

6 Sobre adaptación de la superficie del cerro en forma de terrazas véase S. Gutiérrez y P. Cánovas, 2009, fig. 7. Las características constructivas de este complejo monumental, además de en dicho trabajo, en S. Gutiérrez y J. Sarabia, 2013.

7 Un análisis detallado de este edificio y sus espacios en L. Abad, S. Gutiérrez y B. Gamo, 2000 b; S. Gutiérrez, L. Abad y B. Gamo, 2004 y S. Gutiérrez y P. Cánovas, 2009. 
de ésta y con la misma orientación EsteOeste. Esta edificación, por su disposición y dependencia, debió de tener una función de representación, administración y residencia semejante a algunas residencias episcopales conocidas en Barcelona (GUTIÉRREZ Y CÁNOVAS, 2009:126). Ha sido interpretado como el palacio de una nueva sede episcopal creada a finales del siglo VI o inicios del VII. Ambas construcciones, palatium y basílica, se encuentran articuladas por un espacio abierto desde el que se accede tanto a la basílica por una de sus entradas laterales, como a dos estancias del palatium y cuyo centro ocupa una plaza porticada (GUTIÉRREZ Y SARABIA, 2013:272) ${ }^{8}$.

Este complejo siguió en uso durante los primeros años del siglo VIII, hasta ser abandonado en un momento indeterminado de dicha centuria. Este abandono no parece producirse con la conquista islámica, sino con posterioridad a la misma y estaría acorde con el statu quo que le otorga su inclusión en el Pacto de Teodomiro, donde la ciudad aparece mencionada como Madinat lyyuh. Este hecho explicaría la continuidad funcional de la basílica, y que no haya ningún indicio de su transformación en mezquita (GUTIÉRREZ, GAMO Y AMORÓS, 2003:140). Una vez la iglesia estuvo fuera de uso como edificio de culto, algunas de sus estancias se transformaron en espacios domésticos ${ }^{9}$. A este mismo momento se vincula el uso de un espacio exterior a la iglesia situado al sur del baptisterio. En todos ellos se han documentado unos contextos estratigráficos con ambientes de uso doméstico que evidencian el abandono de la actividad litúrgica. El palatium también sufre transformaciones: el análisis de su secuencia estratigráfica revela un proceso evolutivo que en un primer momento reemplea sus estancias modificando su morfología para adaptarlas a las nuevas necesidades, antes de entrar en un proceso de ruina total ${ }^{10}$. La secuencia estratigráfica del yacimiento y los materiales exhumados en estos contextos hacen pensar que este horizonte se puede situar en el siglo VIII y más probablemente en su segunda mitad (GUTIÉRREZ, GAMO Y AMORÓS, 2003: 140; AMORÓS, 2012).

Sobre este espacio anteriormente ocupado por el área monumental, con la basílica y el palatium ya fuera de uso, arruinados y parcialmente expoliados, se construyó a finales del siglo VIII o inicios del IX, un barrio de viviendas islámicas que incluía alguna estructura de tipo artesanal. Esta área urbana irá densificando su trama urbana con ámbitos domésticos cada vez más complejos (GUTIÉRREZ Y CAÑAVATE, 2010) y continuó habitada ininterrumpidamente hasta el siglo IX o inicios de la centuria siguiente (GUTIÉRREZ LLORET, 2011). La última ocupación habitacional del cerro la encontramos en una de las laderas, donde se construyeron una serie de viviendas parcialmente excavadas en la roca que estuvieron habitadas durante gran parte del siglo XX ${ }^{11}$.

Las fuentes materiales y la toponimia histórica han permitido identificar este asentamiento como la ciudad musulmana de lyyuh o lyih, mencionada en el tratado de capitulación firmado entre 'Abd al-'Azīz ibn Musa y Teodomiro de Orihuela (Tudmîr, Theudimer). La tradicional asimilación de la Madinat lyyuh del pacto de Tudmir con la sede episcopal Eiotana o Elotana, fundada por el Estado visigodo entre finales del siglo $\mathrm{VI}$ y principios de la centuria siguiente, la coincidencia cro-

8 Según S. Gutiérrez y J. Sarabia (en prensa), siguiendo a A. Chavarria "la funzione principale di questi spazi era di raccogliere i fedeli prima della Messa o come ambiente di transito tra la chiesa e l'Episcopio, diventando il luogo percorso dalle processioni che si svolgevano tra uno spazio e l'altro".

9 Es el caso de la habitación meridional aneja al baptisterio, la nave septentrional del mismo y la dependencia aneja al santuario por su lado sur considerada el sacrarium. Véase S. Gutiérrez, 2002.

10 Un análisis detallado de la transformación y reutilización de los espacios del palatium para otros usos y sus contextos estratigráficos en V. Cañavate, J.A. Mellado y J. Sarabia, 2009; S. Gutiérrez, 2011 y S. Gutiérrez y J. Sarabia (en prensa, fig.8).

11 Un estudio reciente propone relacionar los diferentes abandonos urbanos del cerro con episodios sísmicos de magnitudes moderadas que habrían podido destruir la ciudad romana de Ilunum, la visigótica de Elo y la islámica de Madīnat lyyuh (RODRÍGUEZPASCUA et alii, 2013). 
nológica y la entidad de los restos exhumados ha permitido proponer la identificación de la ciudad visigoda de El Tolmo de Minateda con dicha sede episcopal Eiotana o Elotana creada con el fin de administrar los nuevos territorios conquistados pertenecientes a la diócesis de llici que aún permanecía bajo control bizantino ${ }^{12}$.

\section{LA MONEDA EN EL TOLMO DE MINATEDA}

Las campañas de excavaciones arqueológicas que se han realizado desde 1988 en diferentes puntos del yacimiento, han sacado a luz un considerable número de monedas que abarcan un amplio espacio cronológico acorde con el prolongado periodo de existencia de la ciudad. El registro numismático se aproxima a los trescientos ejemplares, en su mayoría de cobre, el 95\% de todo el registro, pero también en plata y oro. La plata no aparece en la ciudad hasta su última fase de existencia, en el siglo IX, en forma de dírhames emirales acuñados en dicha centuria (DOMÉNECH Y GUTIÉRREZ, 2006), a los que hay que añadir parte de un dinero atribuido a Carlomagno acuñado en la Marca Hispánica en la ceca de Roda (DOMÉNECH, 2013). El oro está representado por seis tremises, todos ellos acuñaciones visigodas de baja ley y de cronología tardía.

El registro numismático exhumado en El Tolmo de Minateda arranca en el siglo II a.C. con una exigua representación de emisiones de cecas ibéricas, y continua con las del periodo romano. La moneda romana es mayoritaria en el yacimiento, conformando más de la mitad del registro, aunque su reparto por centurias es muy desigual. Mientras que las épocas republicana e imperial están escasamente representadas, los cobres tardorromanos de los siglos III y IV d.C. conforman el numerario más numeroso, especialmente los de esta última centuria. Este numerario romano bajoimperial es significativo no solo por su importancia cuantitativa en el yacimiento sino, sobre todo, por su contextualización arqueológica: no han sido localizados en estratos de esa cronología, que por el momento no han sido detectados en el yacimiento, sino en los niveles de cronología posterior de los periodos visigodos e islámicos, evidenciando su uso en momentos muy alejados de su fecha de acuñación ${ }^{13}$.

El análisis de los registros monetales del yacimiento a partir de su fecha de emisión ofrece un panorama circulatorio donde abunda la moneda acuñada en los siglos III y IV. Esta visión, que haría pensar en una urbe con gran actividad durante el bajo Imperio, no se corresponde con la realidad que se evidencia cuando se analizan dichos registros teniendo en cuenta el contexto estratigráfico en el que aparecen. Si del periodo tardorromano, del que no se han localizado por el momento niveles arqueológicos en este enclave, contamos con un elevado número de ejemplares monetarios, de la Alta Edad Media, que es el periodo mejor documentado arqueológicamente por la entidad y extensión de los restos exhumados, el registro numismático es considerablemente inferior (GUTIÉRREZ Y DOMÉNECH, en prensa). Dicho registro se compone de un pequeño bronce bizantino con valor de cuatro nummi del tipo cruz/delta (DOMÉNECH Y GUTIÉRREZ, 2005) ${ }^{14}$, seis tremises visigodos, de los que nos ocupamos en este estudio, y un lote de monedas islámicas, tanto andalusíes como foráneas, exhumadas durante la excavación del barrio de viviendas emirales (DOMÉNECH Y GUTIÉRREZ, 2006). Se han recuperado también algunas piezas de cronología más tardía, como son algunas monedas bajomedievales y de época moder-

\footnotetext{
12 Lo mismo sucedió con los territorios de la sede de Carthago Nova, para los que se creó la sede de Begastri. La argumentación sobre la identificación del asentamiento con la sede episcopal y la ciudad islámica en S. Gutiérrez, 2000 a, y S. Gutiérrez, L. Abad y B. Gamo, 2005

13 El estudio de los registros numismáticos de los niveles correspondientes al barrio emiral de El Tolmo puso de manifiesto la amplia circulación de estos cobres tardorromanos en el siglo IX (DOMÉNECH Y GUTIÉRREZ, 2006).

14 Este tipo de piezas, carentes de cualquier referencia a ningún poder emisor, cronología o ceca, han sido consideradas por M. Lechuga (2000) como una emisión local de los imperiales en Carthago Spartaria en base a su frecuente aparición en los contextos bizantinos de la ciudad y a la escasez de este tipo de piezas fuera de ella.
} 
na localizadas a los pies del cerro, y varias monedas contemporáneas halladas en niveles superficiales del yacimiento y relacionadas con la ocupación durante el siglo XX de una de las laderas del cerro en la que se construyeron una serie de viviendas semirrupestres ${ }^{15}$.

Pero esta clasificación de las monedas por periodos cronológicos, basada únicamente en su fecha de acuñación, y ajena a la secuencia estratigráfica en la que fue exhumada, no refleja su momento de uso y puede inducir a plantear hipótesis erróneas. Para analizar el circulante de la ciudad en un determinado momento histórico es necesario atender, no a la fecha de emisión, sino a la de pérdida de la moneda y su deposición en el registro arqueológico, momento en el que deja de circular. La posición que ocupa dentro de la estratigrafía del yacimiento y su vinculación con el resto de materiales con los que se relaciona permite determinar el grado de pervivencia del numerario. Este es el único modo de obtener una visión más real de los modelos circulatorios que funcionaron en cada momento. Así ocurre para la etapa visigoda de la ciudad de El Tolmo de Minateda, la sede episcopal de Eio, donde encontramos seis tremises emitidos por el Estado visigodo que en principio se podrían considerar como el único numerario de este periodo. Sin embargo, el estudio del registro numismático contextualizado dentro de la secuencia estratigráfica del yacimiento permite observar un circulante mucho más abundante que sugiere un importante grado de monetización en esta etapa.

\section{EL CIRCULANTE DE LA CIUDAD VISIGODA: COBRE Y ORO}

Los trabajos arqueológicos llevados a cabo hasta el momento en la ciudad visigoda de El Tolmo de Minateda se han centrado en el complejo monumental de carácter religioso situado en la parte alta del cerro y en la vaguada, conocida como El Reguerón, que conforma el acceso más fácil hacia la zona alta. En esta vaguada se han excavado dos viviendas de ese periodo, el baluarte defensivo que protege dicha entrada y un vertedero extramuros que se formó junto a la fortificación (GUTIÉRREZ, 2000 b). Tanto en el complejo monumental como en El Reguerón han sido exhumadas monedas vinculadas a los niveles visigodos del yacimiento, aunque los registros de una y otra zona ofrecen importantes diferencias, acordes con la distinta naturaleza de los espacios donde han aparecido. Los registros numismáticos procedentes de espacios domésticos, limitados a las dos viviendas mencionadas anteriormente ${ }^{16}$, son exclusivamente viejos bronces romanos; mientras que los recuperados en la zona alta del cerro incluyen también monedas de oro visigodas, sin duda relacionadas con el carácter de la zona excavada: un espacio arquitectónico vinculado con la nueva sede episcopal. Contamos pues con datos parciales en cuanto a la ciudad visigoda se refiere y, en el estado actual de las investigaciones, no es posible conocer el circulante del emplazamiento en esta etapa más que en unas áreas limitadas y concretas, pero la importancia de uno de esos espacios, el complejo religioso, y la contextualización estratigráfica de los registros monetales analizados, justifican el estudio de los materiales numismáticos en él exhumados.

El registro numismático de las zonas estudiadas correspondientes a la fase visigoda de la ciudad está compuesto por seis monedas de oro, tremises acuñados por el Estado visigodo, y numerosas piezas de cobre de adscripción romana que, sin duda, circularon por la ciudad visigoda de El Tolmo.

\section{Los cobres romanos en la ciudad visigoda}

Además de las emisiones estrictamente visigodas localizadas en el ámbito monumental de la ciudad, los trabajos arqueológicos han permitido recuperar varias monedas de cobre, tanto en la propia zona monumental de la parte alta de la ciudad, como en el área

15 Un estudio arqueológico y etnográfico de una de dichas casas en P. Cánovas, V. Cañavate y J. Sarabia, 2010. 16 La mayor parte de los espacios domésticos de la fase visigoda del yacimiento permanecen aún sin excavar. 
del Reguerón. Estos cobres son mayoritariamente tardorromanos, siendo especialmente abundantes los del siglo IV d.C.

Por lo que se refiere a la zona alta, en los niveles de construcción, uso y derrumbe del complejo religioso visigodo, anteriores al inicio de las primeras construcciones islámicas, el registro numismático proporciona, además de seis tremises visigodos, más de medio centenar de monedas de cobre que aparecieron dispersas por toda el área excavada. Dichas monedas sin duda formaban parte del circulante en uso de la ciudad, a pesar de que la autoridad emisora de dichas piezas no era el Estado visigodo. Estos cobres, mucho más numerosos en el yacimiento que los tremises, debían ser monedas de uso común que conformaban el circulante mayoritario de la civitas, aportando las especies monetarias de valores más bajos.

Su posición estratigráfica no deja lugar a dudas a este respecto. Algunos nummi del siglo IV d.C. han sido exhumados tanto en los niveles de construcción del complejo religioso, como uno a nombre de Constantino acuñado en la ceca de Arelate entre el 336 y el 337 d.C. ${ }^{17}$, como en los niveles de frecuentación del palatium. También los estratos que conforman el derrumbe de estos edificios, especialmente los del palatium, contenían cobres de adscripción romana, mayoritariamente bajoimperiales, pero también algunos más antiguos como ases y sestercios de los siglos | y || d.C., un divisor de época de Augusto ${ }^{18}$, y alguna posible pieza anterior ${ }^{19}$. Así, en el nivel de derrumbe del reducido espacio de la GU 69, una pequeña habitación de apenas 9 m2 donde se hallaron bloques caídos de opus signinum de una segunda planta y el arranque de una escalera ${ }^{20}$, se exhumaron cinco monedas, todas ellas romanas, de las que al menos tres son emisiones del siglo IV d.C. y otra posiblemente de la misma centuria.

En la zona baja del yacimiento el registro numismático recuperado procede de tres espacios de características bien distintas: los ambientes domésticos, la construcción defensiva y el basurero extramuros. En los espacios domésticos existentes junto a la puerta de entrada a la ciudad, se han exhumado una serie de monedas, todas ellas cobres romanos, en contextos que resultan significativos. Como ejemplos podemos mencionar un nummus que presenta un alto grado de desgaste $y$ una perforación, datado en la primera mitad del siglo IV d.C., que ha sido exhumado en el nivel de construcción de las casas visigodas ${ }^{21}$; otro de la misma centuria, que se encontraba sobre el pavimento de una de las viviendas ${ }^{22}$; o un antoniniano de Claudio II de ceca Roma, datado en 268-269 d.C. que se localizó sobre el pavimento de un patio junto al muro de una de las viviendas ${ }^{23}$. Aunque el 50\% del numerario recuperado en estas casas visigodas corresponde al siglo IV d.C., existen ejemplares más antiguos como son un as de Nerón datado entre el 54 y el 68 d.C., y otro as del siglo II a.C. hallados ambos en muros de fábrica visigoda 24 .

Al igual que ocurre en estas viviendas, la excavación del baluarte visigodo que se construye junto a ellas para proteger la entrada

\section{U.E. 62829}

18 U.E. 62238.

19 La presencia de moneda altoimperial, republicana e incluso más antigua en contextos altomedievales es un fenómeno conocido que se ha documentado en diferentes lugares de la geografía peninsular. Algunos ejemplos son los casos de Recópolis, donde se han exhumado monedas de cronología altoimperial en los niveles visigodos (CASTRO, 2008:137), o las excavaciones urbanas de Cartagena, donde ha aparecido un as ibérico en estratos bizantinos (LECHUGA, 2000:336); o el nivel de abandono del teatro romano de Cádiz, donde se localizaron ases de Gades del siglo II a.C. y piezas republicanas y altoimperiales junto con moneda bajoimperial de Teodosio, Constancio II, Valentiniano y Valente (LÓPEZ Y BLANCO, 1999).

20 Este espacio podría interpretarse como el inicio de una torre o campanario a tenor de sus dimensiones y de los contrafuertes que refuerzan el muro occidental desde el vestíbulo (GUTIÉRREZ Y CÁNOVAS, 2009:96 y 125).

21 U.E. 3018.

22 U.E. 1454

23 U.E. 1587.

24 U.E. 1121 y 1059 respectivamente. 
de la ciudad, ha proporcionado un registro numismático exclusivamente de cobre que abarca también una cronología amplia. La contextualización estratigráfica de estas monedas no deja lugar a dudas en cuanto a su circulación en la etapa visigoda y posteriormente en la islámica ${ }^{25}$. Sirva como ejemplo el hallazgo de una fracción radiada romana salida del taller de Cízico entre el 295 y el 299 d.C. que se encontraba en el paquete estratigráfico situado entre el último pavimento de la puerta visigoda y el primero de la islámica ${ }^{26}$.

Al exterior del baluarte que protegía la entrada de la ciudad, se acumularon una serie de deposiciones que formaron un vertedero de dimensiones considerables. La excavación arqueológica de este basurero extramuros permitió distinguir hasta tres fases deposicionales que contenían una importante cantidad de materiales cerámicos, todos ellos de adscripción visigoda, y similares a los procedentes del conjunto de espacios domésticos construidos sobre el baluarte, del que parece ser contemporáneo. Los registros cerámicos nos sitúan cronológicamente en un momento avanzado del siglo VII y quizás los vertidos se prolongaran durante los primeros años de la centuria siguiente (GUTIÉRREZ, GAMO y AMORÓS, 2003:134). Entre los depósitos de los vertidos fueron hallados algunos cobres, todos ellos de filiación romana y mayoritariamente de cronología tardía, fundamentalmente del siglo IV d.C., pero también algún ejemplar más antiguo como un as republicano del tipo Jano bifronte y proa de nave.

Estos datos que nos ofrece el registro numismático debidamente contextualizado nos muestran que, en esta área de entrada a la civitas, la presencia de moneda no era extraña. Pero no era la moneda emitida por el Estado visigodo, que por su mayor valor debió de circular menos en determinados ambientes ${ }^{27}$, sino los viejos cobres tardorromanos que se habían mantenido en circulación. Su uso y su pérdida en el baluarte defensivo, en los espacios domésticos y en el basurero extramuros así lo evidencian.

Este numerario de cobre romano difícilmente puede considerarse residual, dada la frecuencia con que aparece en el yacimiento y la imposibilidad de que provenga de etapas más antiguas del asentamiento, ya que, en el estado actual de la investigación, todo parece indicar que durante los siglos III y IV d.C. Ia ciudad debía estar prácticamente despoblada, o al menos sin actividad suficiente que explique la presencia de un numerario de esas centurias tan abundante en el yacimiento. Su contextualización en estratos arqueológicos nos permite obtener una visión fiable de la dinámica circulatoria en esta civitas en los últimos tiempos del reino visigodo, y nos ofrece información de primera mano sobre la duración real en el tiempo del fenómeno de la pervivencia de los viejos cobres tardorromanos como circulante en uso ${ }^{28}$.

\section{El numerario visigodo}

El numerario de acuñación visigoda recuperado en la antigua civitas de Eio hasta el momento, está formado por seis monedas de oro ${ }^{29}$, todas ellas exhumadas en el área monumental en torno a la basílica y el palatium. Se trata de tremises acuñados en diferentes cecas entre finales del siglo VII y principios del VIII que corresponden a los reinados de Ervigio

25 A los ejemplos aquí expuestos referidos a los niveles visigodos del yacimiento, se pueden añadir los correspondientes a la fase islámica tratados en Doménech y Gutiérrez, 2006, donde se analizan algunos ejemplos de numerario romano documentados en niveles de construcción, uso y abandono de las viviendas islámicas, tanto en la parte alta del cerro como en la zona de la puerta.

26 U.E.1246.

27 Tampoco ha sido localizado por el momento en el yacimiento ningún ejemplar de los supuestos cobres acuñados en época visigoda. Sobre dicho numerario véase M. Crusafont (1984, 1988, 1990, 1994 y 1998). La síntesis de esta problemática puede seguirse en C. Doménech (2009:738-740) y R. Pliego (2009:I-188-190).

28 Dicha pervivencia, ampliamente documentada en los trabajos de T. Marot para otros enclaves (MAROT, 1990, 1996, 1997 y 2002; MAROT y LLORENS 1995, 1996; MAROT, LLORENS y SALA 2000), ha sido tratada en trabajos anteriores a los que remitimos. Véase Doménech y Gutiérrez (2006:368), y Doménech (2009:741-743) con la bibliografía correspondiente.

29 De la existencia de algunos de estos tremises se han ido dando noticias parciales en Doménech y Gutiérrez, 2005 y 2006; Doménech, 2013 y Gutiérrez, 2011. Abordamos aquí su estudio numismático. 
(680-687), la etapa de gobierno conjunto de Egica y Witiza (694/5-702), y la de Witiza en solitario (700-710) ${ }^{30}$. Su fecha de acuñación se sitúa en un momento tardío, acorde con los datos proporcionados por el conjunto de los restos arqueológicos estudiados para esta fase. Abarcan un periodo cronológico de apenas 30 años, entre los años 680 al 710, por lo que su momento de uso debió situarse, en algunos casos, ya entrado el siglo VIII, siempre con anterioridad a la construcción del barrio emiral, según indica su posición dentro de la secuencia estratigráfica del yacimiento.

Proceden de cinco cecas distintas: Cesaragusta, Toleto, Tucci, Córdoba e Ispali, todas ellas activas prácticamente a lo largo de toda la etapa visigoda a excepción de la de Tucci (Martos, Jaén), cuya producción fue más intermitente. Algunas de estas cecas están entre las más productivas del periodo ${ }^{31}$. Según los estudios de D. M. Metcalf (1999), de Ispali proceden el 15\% del total de todos los tremises conservados, de Toleto otro 15\% y de Córdoba el $8 \%$. De estas tres cecas, junto con Mérida, procederían el $60 \%$ de las monedas conservadas. Estos porcentajes se han mantenido prácticamente inalterados a pesar del aumento en el número de piezas conocidas en la actualidad $^{32}$. Por otro lado hay que tener en cuenta el gran vacío de talleres existente en el centro de la provincia Carthaginensis, hace que algunas de las cecas de las que salieron los tremises localizados en yacimiento como son Tucci y Toleto estén entre las más próximas a la civitas.

Los tremises exhumados en el Tolmo de Minateda presentan algunos aspectos formales que los convierten, en algunos casos, en tipos inéditos o poco frecuentes. Por ello, creemos de interés el detallar algunos de sus rasgos tipológicos más representativos.

El tremís más antiguo es una acuñación a nombre de Ervigio (680-687) (Figura 3). Procede de Ispali, una de las cecas más estables

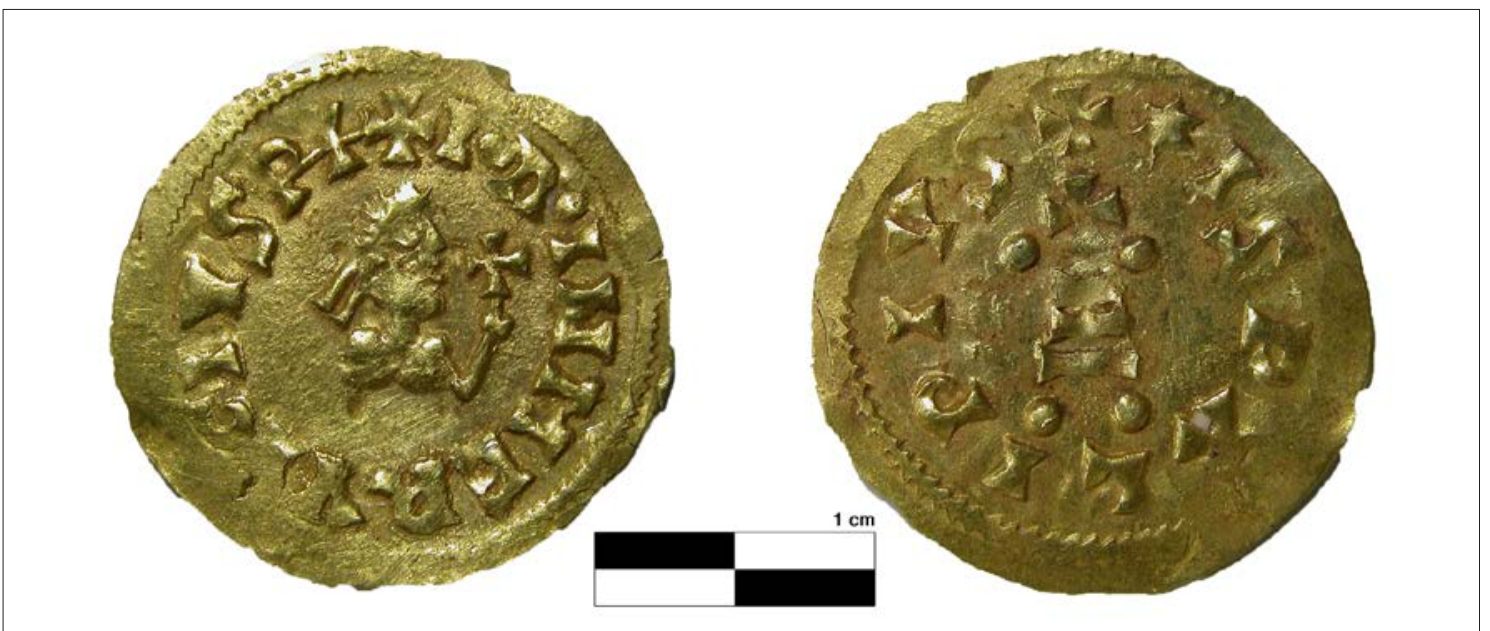

Fig. 3. Triente de Ervigio ceca Ispali. Foto: Museo de Albacete.

30 Se sigue la referencia cronológica utilizada por J. Vico, M.J. Cores y G. Cores en el Corpus Nummorum Visigothorum (2006:77), que arranca las emisiones de Witiza en el año 700, momento en que recibe la unción regia, todavía en vida de su padre Égica. Según J.M. de Francisco (2009:165) dicha unción sería "el último paso ceremonial para igualarle al rey senior en dignidad, incluso en la sacralización de su persona". Véase también nota 36.

31 Aunque no es este el lugar para abordar con profundidad la cuestión de los talleres de acuñación, parece interesante mencionar la interpretación de I. Martín Viso. Para este autor las cecas serían un elemento fundamental en el entramado fiscal funcionando como grandes focos de captación de tributos. "Las cecas jugaban un papel esencial en el fenómeno de la adaeratio, pues en ellas es donde se hace efectiva la transformación del producto en especie en moneda." El volumen de piezas conservadas de algunas de ellas, cuyas emisiones fueron más o menos constantes, "demuestra la existencia de una tributación constante y relativamente abundante que se centraliza en estos focos episcopales..." (MARTín VISO, 2013:77).

32 Los datos más recientes, detallados por reinados, provincias y cecas, proporcionados en número de ejemplares por R. Pliego (2009:II- tabla 25, pp.47-50), no varían significativamente estas cifras generales. De los cálculos realizados a partir de dicha tabla resultarían los siguientes porcentajes: Ispali 16.68\%, Toleto 13.86\%; Córdoba 7.38\% y Emerita 20.67\%. 
y regulares, no solo de la Baetica, sino del conjunto del reino visigodo, ya que acuñó moneda sin interrupción a partir del reinado de Leovigildo hasta el de Witiza. El ejemplar que presentamos está considerado como rarísimo dado el escaso número de piezas conocidas $^{33}$. El anverso presenta un tipo tardío que empieza a usarse bajo el gobierno de Wamba y se mantiene hasta el de Witiza ${ }^{34}$, consistente en representar el busto del rey de perfil con una cruz en la mano ${ }^{35}$. El reverso es de cruz griega sobre tres gradas, observándose dos puntos bajo las mismas, y otros dos situados uno a cada lado de la parte inferior de la cruz. Presenta una estrella en la leyenda del reverso situada entre la cruz patada de inicio y la "I" de Ispali. Este tipo de signos, junto con otros como anillos, glóbulos o palmas, llamaron la atención de F. Llopis, quien los interpretó como distintivos de las diferentes emisiones (LLOPIS, 1941: 95-96). Otros autores como P. Bartlett, G. Cores y M.C. Cores (2005) han seguido esa misma interpretación para las marcas presentes en las leyendas de las emisiones de la ceca de Ispali bajo el reinado de Sisebuto, aunque sin descartar que se trate de meros elementos ornamentales. El mismo signo o muy similar aparece como motivo central del reverso sustituyendo a la cruz en algunos ejemplares de la Baetica durante el reinado conjunto de Égica y Witiza.

Un segundo tremís, siguiendo un orden cronológico, sería el acuñado bajo el reinado conjunto de Égica y Witiza (Figura 4) (694/5702). Procede del taller de Cesaraugusta, ceca que estuvo activa prácticamente en todos los reinados desde Leovigildo hasta Achila. El tipo de anverso es uno de los habitualmente usados en los reinados conjuntos: dos bustos afrontados con una cruz entre ambos ${ }^{36}$. El tipo de reverso es el monograma de la ceca con

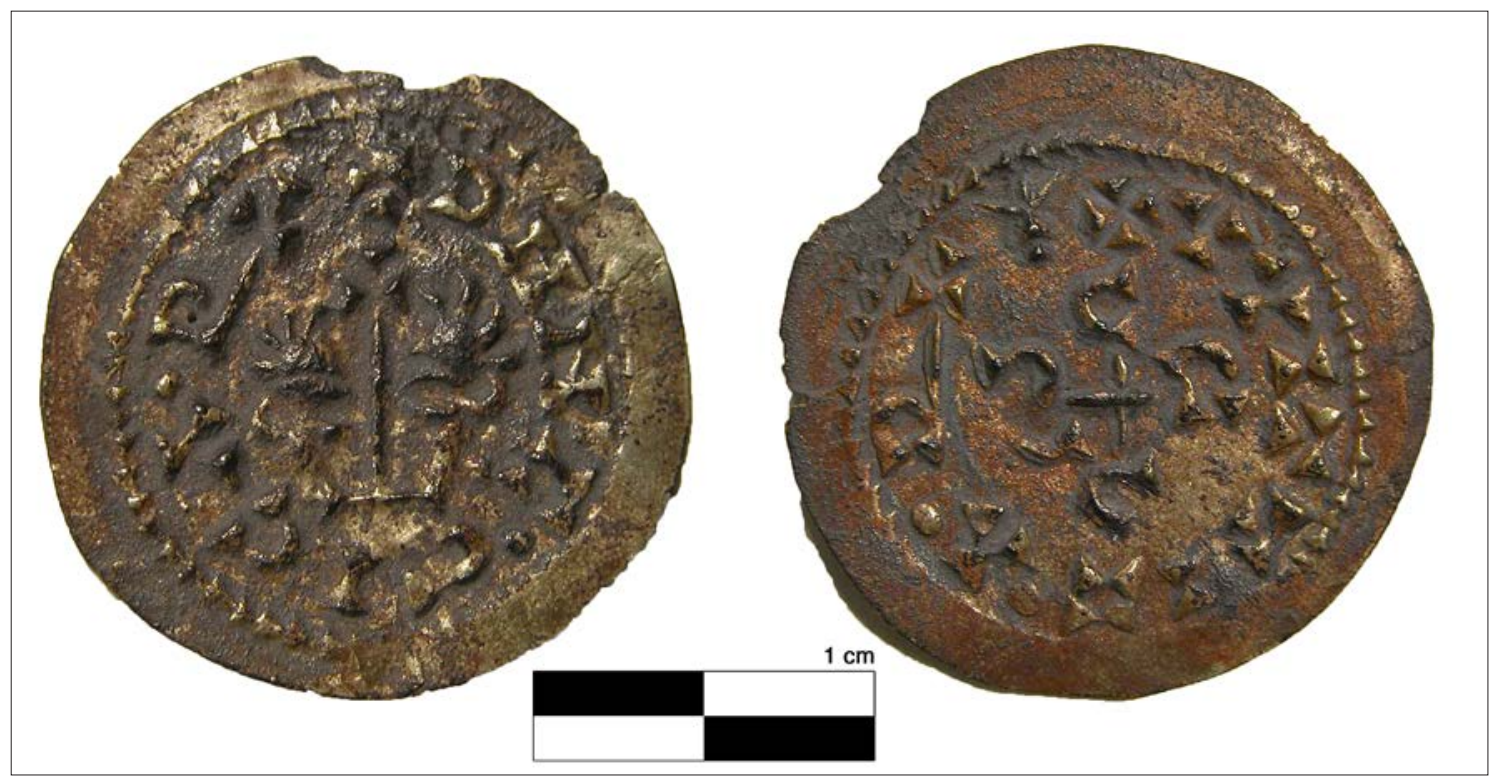

Fig. 4. Triente de Égica y Witiza ceca Cesaraugusta. Foto: Museo de Albacete.

33 R. Pliego (2009: II-388) da noticia de 4 piezas además de la aquí estudiada. En el Corpus Nummurom Visigothorum (2006:493, tipo 492) es calificada como "RRR"(rarísima), mientras que el catálogo de G.C Miles (1952:382, tipo 408) solo recoge un ejemplar.

34 Un estudio sobre la iconografía monetal en los últimos tiempos del mundo visigodo como instrumento de propaganda monárquica en R. Pliego (2011).

35 En algunos ejemplares la cruz prolonga su trazo vertical por lo que también ha sido descrita como un cetro crucífero (MILES 1952: 52 tipo $2 \mathrm{jj}$ ), o simplemente como un cetro (PLIEGO 2009:I-168 tipo 15 c). En la pieza que nos ocupa la cruz no parece adoptar forma de cetro por lo que preferimos utilizar la descripción de J. Vico, M.C. Cores y G. Cores (2006:136 tipo 3 anverso).

36 J.M. de Francisco ha hecho notar que, a diferencia de los tipos de reyes asociados usados en Bizancio donde los reyes se representan con distinto tamaño o edad, en la iconografía de las monedas de Égica y Witiza aparecen en plena igualdad ambos reyes asociados y, en algunas piezas visigodas, se ve a ambos reyes agarrando juntos la cruz sin mostrar supremacía de uno sobre otro como ocurre en la moneda bizantina. (FRANCISCO de, 2009:167). 
"S" retrógrada. Presenta un símbolo de tipo vegetal a modo de palma insertado al final de la leyenda del reverso, entre la abreviatura de Rex y la cruz patada que da comienzo a la inscripción. Este signo, junto con otros como astros o glóbulos frecuentes en algunas emisiones de la Baetica, se encuentra también con cierta frecuencia en las acuñaciones conjuntas de Égica y Witiza con reverso de monograma. Concretamente una palma como la que presenta la pieza que aquí estudiamos la encontramos en las cecas de la Baetica en diferentes posiciones junto al monograma, convirtiéndose, en el caso del taller de Egabro, en motivo central del reverso. Fuera de la Baetica, su posición habitual es el final de la leyenda del reverso, apareciendo tanto en ejemplares de Cesaragusta como de Toleto o en la ceca lusitana de Elvora.

Del reinado de Witiza en solitario (700-710) contamos con cuatro tremises de diferentes cecas. Uno de ellos procede del taller de Córdoba (Figura 5), otra de las ciudades que mantienen su producción monetaria durante todo el periodo desde Leovigildo a Witiza. Presenta en el anverso un busto a la derecha y en el reverso una cruz griega sobre tres gradas bajo las cuales figuran tres puntos. La leyenda del anverso carece de cruz de inicio, mientras que el nombre de la ceca en el reverso aparece acompañado del epíteto de tradición romana "patricia" 37.

Una segunda pieza del mismo gobernante procede de Toleto (Figura 6). Como capital del reino, fue una ceca muy activa que acuñó durante todos los reinados. Bajo el gobierno de Witiza ocupa el segundo lugar en número de ejemplares conocidos (PLIEGO, 2009:II-44). El anverso presenta el busto del rey de perfil hacia la derecha. En el reverso se observa una cruz latina sobre dos gradas en cuya parte inferior aparece un punto en el interior de medio círculo, a cuyos lados encontramos dos puntos más. En la leyenda del reverso figura la ceca seguida del epíteto "pius" y un signo a modo de palma entre el final de la leyenda y la cruz de inicio.

Otros dos tremises a nombre de Witiza proceden de la ceca de Tucci, actual Martos, en la provincia de Jaén, que fue sede episcopal. Se trata de un taller de producción intermitente que comienza sus emisiones en el siglo VII bajo el reinado de Sisebuto, coincidiendo con la campaña de conquista de estos territorios a los bizantinos, aunque el periodo más activo

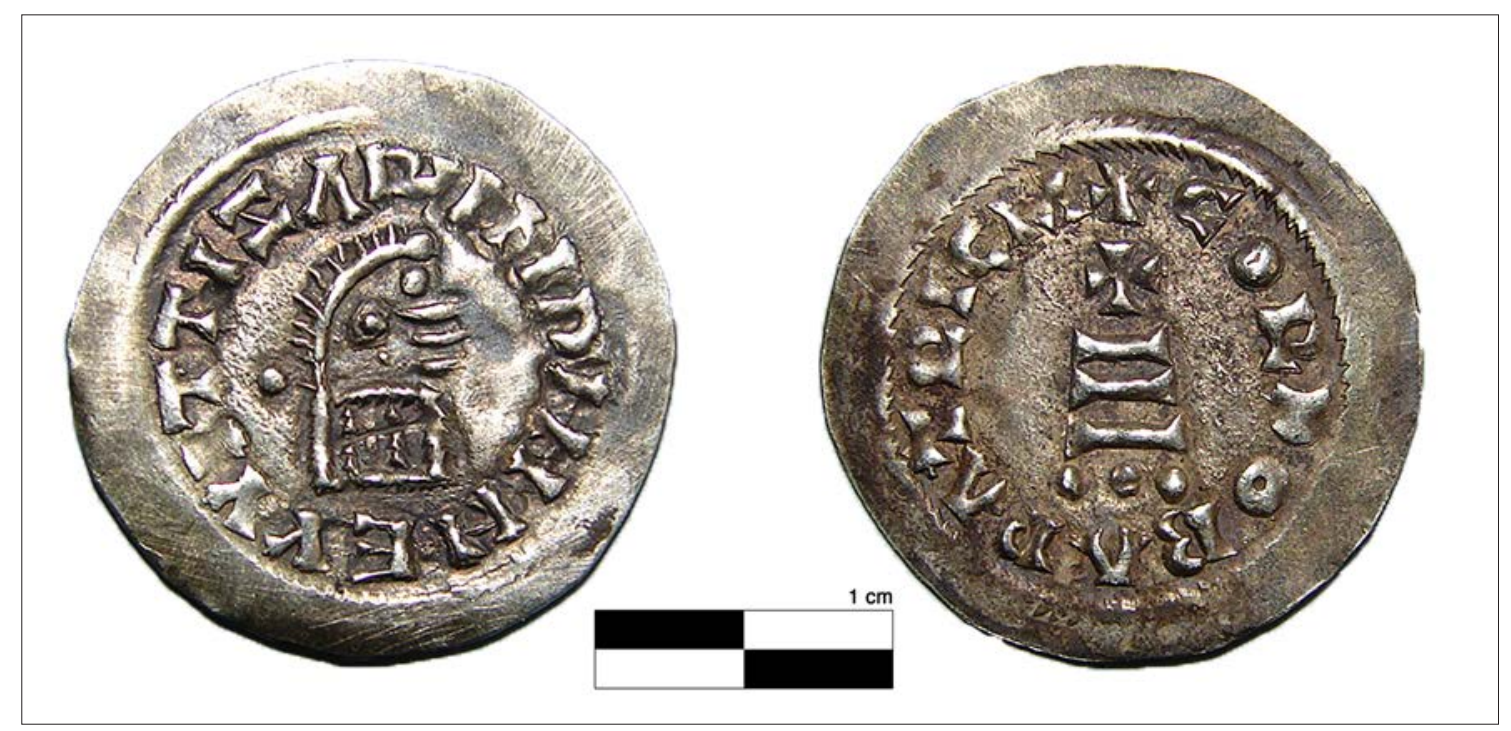

Fig. 5. Triente de Witiza ceca Córdoba. Foto: Museo de Albacete.

37 Este epíteto se recupera en tiempos de Chindasvinto y continuará en uso en las monedas hasta el reinado de Witiza (VICO, CORES y CORES, 2006:129). 


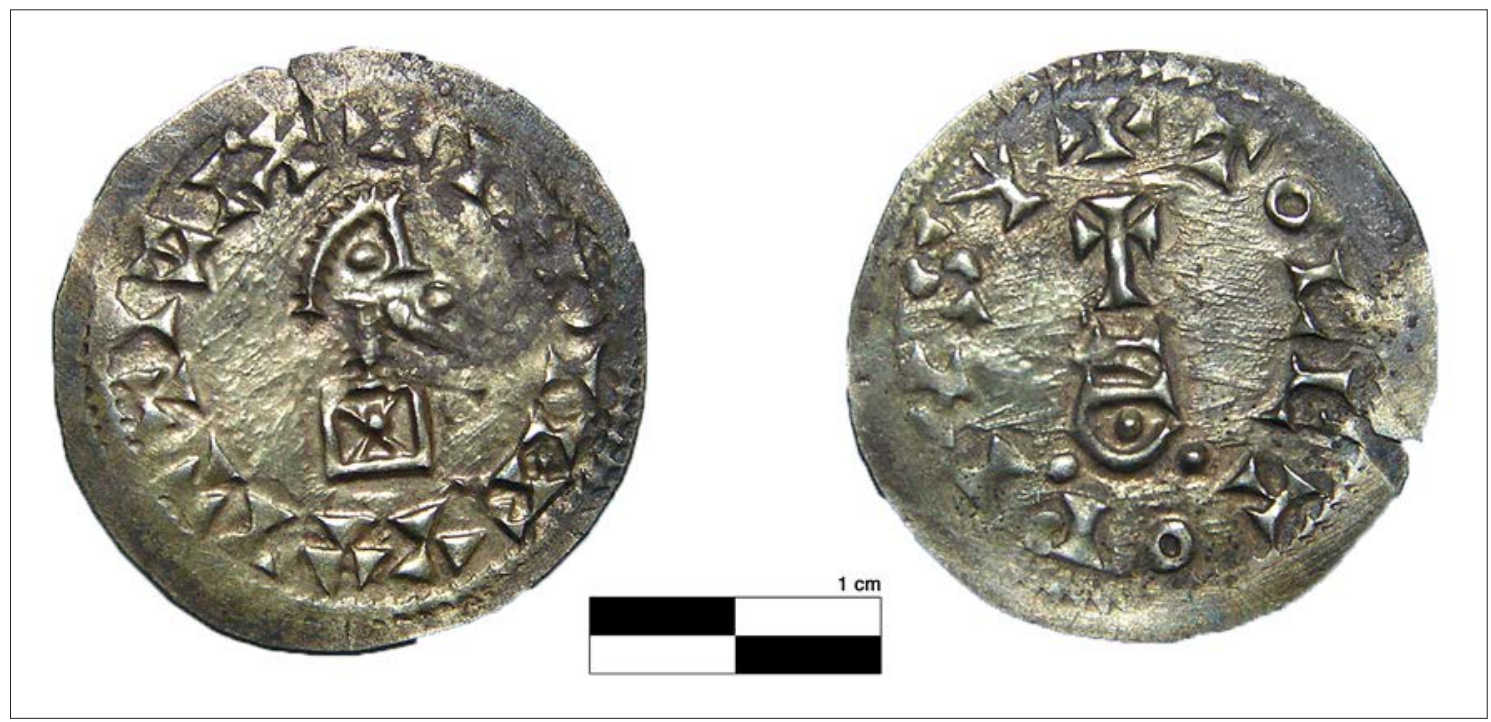

Fig. 6. Triente de Witiza ceca Toleto. Foto: Museo de Albacete.

del taller parece ser el reinado de Suintila. En el año 642, con la muerte de Tulga, detiene sus acuñaciones, que se retomarán momentáneamente bajo el gobierno de Ervigio, cambiando por primera vez el busto frontal del monarca, que adopta ahora una posición lateral. Después de su mandato, esta ceca volverá a abrirse con la asociación de Witiza al trono de Égica, período en el que durante mucho tiempo se dieron por finalizadas las acuñaciones de este taller. Sin embargo, en 1985 se publicaba un ejemplar fragmentado acuñado bajo el reinado de Witiza en solitario que parece proceder de un hallazgo casual en algún lugar de Andalucía (CHAVES, 1985 y 1991-3). El hallazgo de dicho ejemplar demostraba que el periodo de actividad de la ceca de Tucci se prolongaba hasta dicho reinado. Desde entonces han aparecido tres ejemplares más, dos de ellos en El Tolmo de Minateda.

Uno de estas piezas de la ceca de Tucci acuñada bajo el gobierno de Witiza en solitario hallada en el yacimiento presenta en el anverso el busto de frente, tradicional de esta ceca hasta Ervigio, y el reverso de cruz sobre tres gradas (Figura 7). Esta combinación de tipos en anverso y reverso es tardía ya que, si

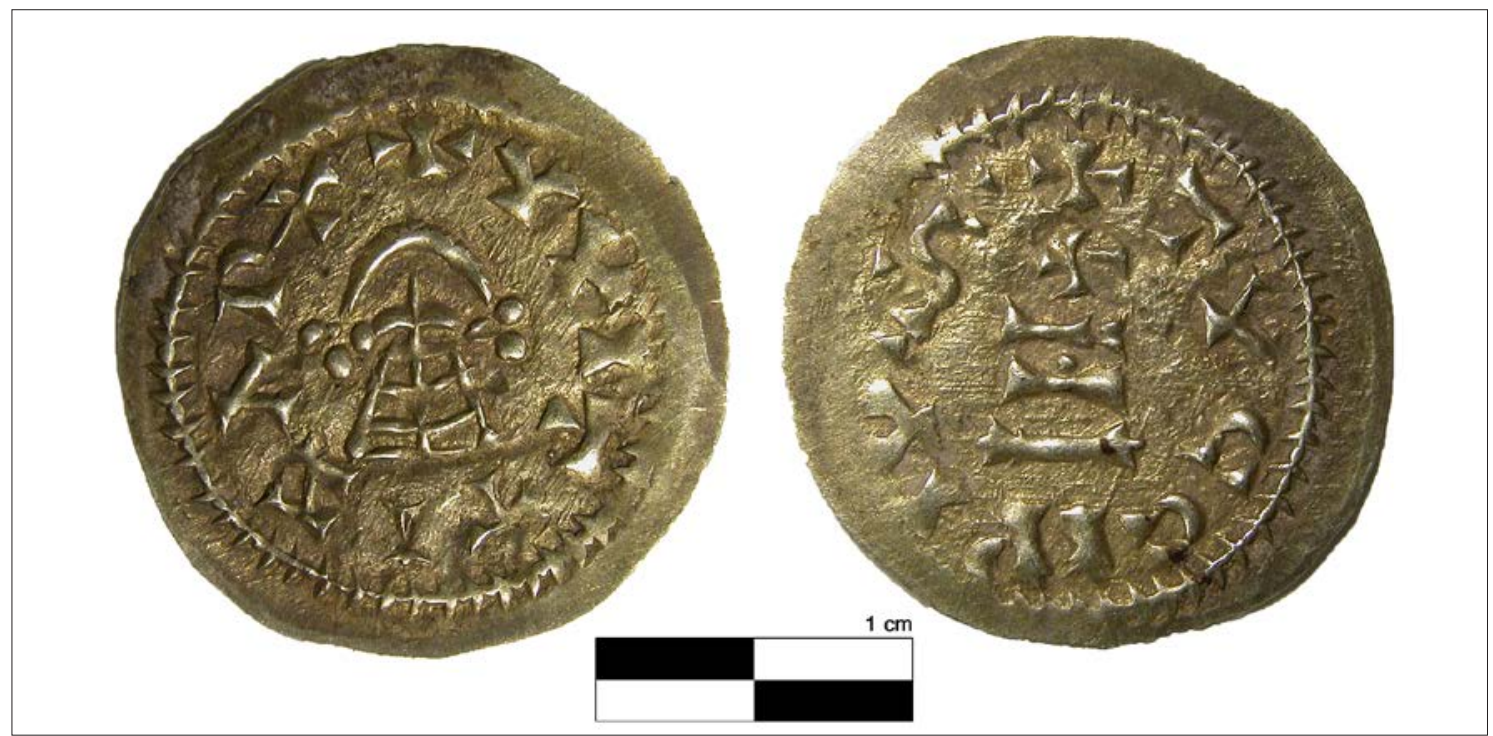

Fig. 7. Triente de Witiza ceca Tucci. Foto: Museo de Albacete. 
exceptuamos las acuñaciones de Chintila en Narbona entre el 636 y el 639 de la que únicamente se conoce un ejemplar, solo la encontramos a partir del reinado de Wamba, en los últimos momentos de vigencia del Estado visigodo, perdurando hasta las emisiones de Achila en la Narbonense 38 (VICO, CORES y CORES, 2006). Sus leyendas son muy simples: el nombre del rey en el anverso sin ningún tipo de invocación ni epíteto, y el nombre de la ceca con el calificativo de "pius" en el reverso. La "s" de "pius", además de ser retrógrada, presenta tres marcas triangulares: una al inicio, otra sobre la letra tumbada y una última al final.

El cuarto tremís que pertenece a las emisiones de Witiza, es del tipo busto a la derecha en anverso y cruz griega sobre tres gradas en el reverso. Presenta un nombre de ceca poco común: Tuccus (Figura 8), que en principio podríamos asimilar a Tucci, que es la forma toponímica habitual mencionada en las leyendas monetales ${ }^{39}$. Además del nombre de la ceca, este ejemplar presenta una leyenda en el reverso novedosa e interesante, ya que repite la abreviatura "In Dei Nomine". Esta invocación había empezado a utilizarse en la leyenda del anverso precediendo al nombre del monarca desde las emisiones de Chindasvinto, a mediados del siglo VII. En el caso del tremís que presentamos la invocación aparece dos veces: en su lugar habitual del anverso y repetida también en la leyenda del reverso precediendo al nombre de la ceca. Esta circunstancia anómala, que no se da en ningún otro ejemplar conocido hasta hoy, hace de él, por el momento, una pieza única. La presencia de esta invocación a la divinidad en la leyenda del reverso sin que le siga el nombre del monarca, tal vez tenga que ver con un mantenimiento anómalo de la estructura de la leyenda del reverso de las monedas

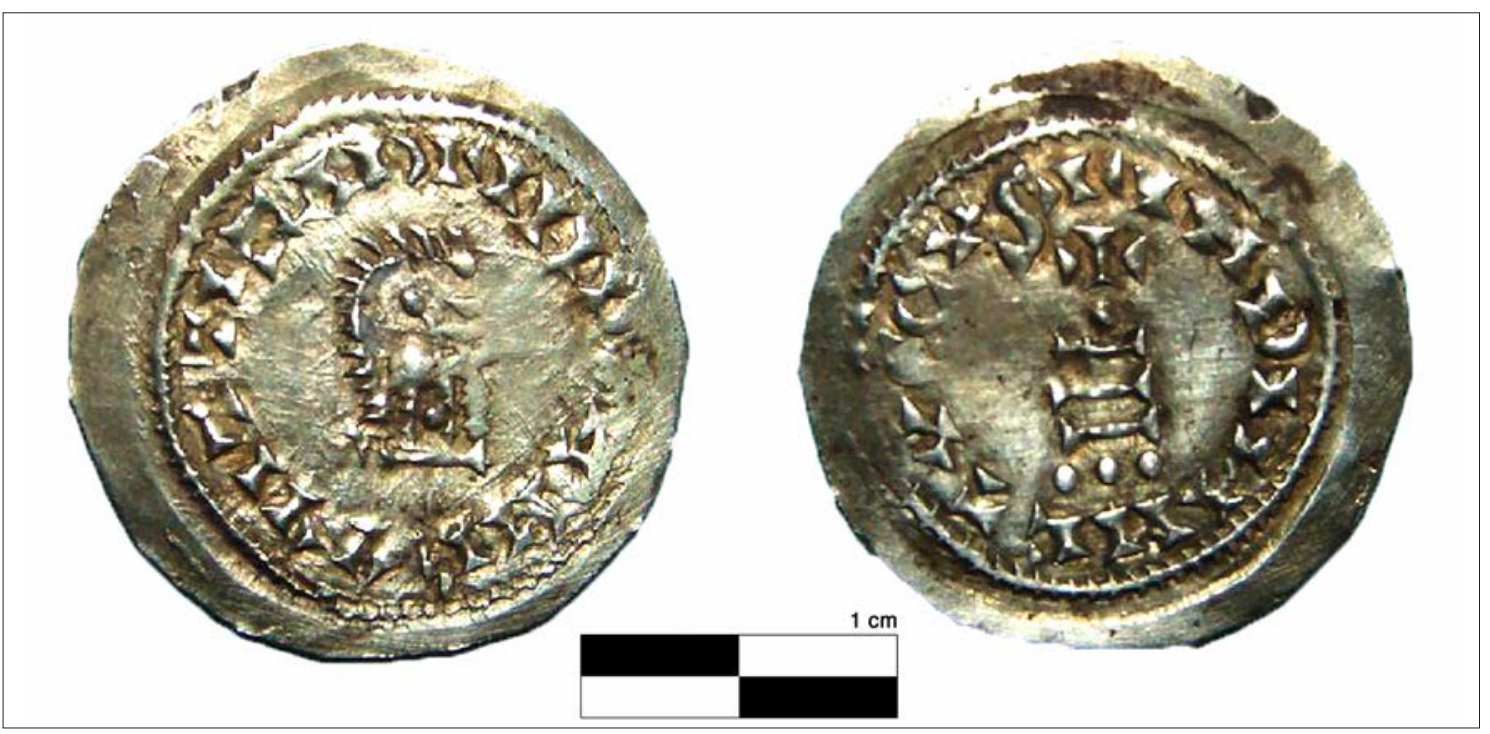

Fig. 8. Triente de Witiza ceca Tuccus. Foto: Museo de Albacete.

38 Esta misma combinación de tipos figura en los tremises de Recesvinto (642-672) con cabeza de frente dentro de una gráfila interior en anverso y reverso de cruz sobre gradas, también con gráfila interior. Sin embargo, estas piezas se consideran como un grupo tipológico diferente (grupo IX del Corpus Nummorum Visigothorum), grupo que se adscribe exclusivamente a este rey en sus emisiones de la ceca de Córdoba y del que se conocen muy pocos ejemplares, por lo que está considerado un tipo rarísimo.

39 Según J.A. Correa, los topónimos de las monedas visigodas "testimonian un momento del largo proceso de reducción y desaparición última del sistema casual" y, en general, en ellos se va perdiendo el uso de las declinaciones en aras de su función denominativa (CORREA 2006:237). En cuanto a Tucci, otra variante toponímica, que no afecta a la identificación de la ceca, es la grafía TVCI con una sola "C", que es la forma más antigua que aparece en las monedas. La encontramos desde el comienzo de las emisiones hasta el reinado de Chintila. Es en las monedas de Sisenando cuando empezamos a encontrar algún ejemplar donde el nombre del taller aparece escrito con doble "C". A partir de Tulga, la grafía TVCCI sustituye a la anterior, quedándose como grafía única en todos los casos en los que el nombre de la ceca figura en la leyenda circular. Cuando se presenta en forma de monograma nunca figura la doble "C". Para R. Pliego la forma Tuccus sería "un error según el cual la leyenda del anverso se habría grabado en el reverso" (PLIEGO 2009: II-478 nota 1381). 
del periodo anterior. La fórmula invocatoria podría estar tomada de las acuñaciones conjuntas con Égica. En las emisiones de la propia ceca de Tucci aparecía "In Dei Nomine" en el reverso acompañando al nombre del segundo soberano. A la muerte de Égica las leyendas debieron mantenerse pero, en lugar de mencionar dos soberanos, solo figura Witiza, cuyo nombre pasa a ocupar la leyenda del anverso, mientras que en la del reverso figurará ahora el nombre de la ceca manteniendo erróneamente un "In Dei Nomine" que ya no tendría ningún sentido y carecería de toda función. En el reverso el tipo es el tradicional de cruz sobre gradas.

De entre los rasgos materiales de los tremises visigodos que nos ocupan cabe mencionar el referido a la ley de las monedas. Aunque carecemos de analíticas sobre la composición metalográfica de los tremises hallados en El Tolmo de Minateda, es fácilmente apreciable a simple vista que se trata de acuñaciones hechas en oro de baja ley como es habitual en estas emisiones tardías. Esta circunstancia aparece más acentuada en las cuatro piezas acuñadas bajo el reinado de Witiza en solitario, cuya apariencia recuerda más a una moneda plata que a una de oro ${ }^{40}$. De hecho este aspecto externo se debe a la presencia de un alto porcentaje de plata en la aleación metálica de estas monedas, plata que fue aumentando su presencia en los cospeles a partir de la segunda mitad del siglo VII en detrimento de la cantidad de oro presente en las monedas. Según los datos aportados por J. Vico, M.J. Cores y G. Cores (2006:101 y ss.) basándose en los análisis realizados por M. Gomes, J.M. Peixoto y J. Rodrigues (1995) y en los llevados a cabo para su propio estudio, en el reinado de Ervigio el porcentaje de oro presente en los tremises se situaba aproximadamente en el 67\%, disminuyendo en el reinado de Égica a un 58\% para llegar al 48\% en los ejemplares de su reinado conjunto con Witiza. Es bajo el gobierno de este rey en solitario cuando el oro alcanza su porcentaje más bajo en toda la historia de la moneda visigoda, situándose en torno al $45 \%$ y siendo superado por la plata, presente en una proporción mayor, lo que explica el aspecto plateado de sus tremises.

La tendencia de pérdida de calidad constatada a nivel metalográfico se acompaña de un proceso similar en lo que se refiere a los aspectos metrológicos. En origen, el tremís, como tercio del solidus romano de 4,54 g., debía ajustar su peso al patrón romano ofreciendo un peso teórico de 1,51 g. Sin embargo, la realidad metrológica de los ejemplares conocidos ofrece desviaciones notables que tienen que ver con las distintas áreas peninsulares, los talleres de acuñación y las circunstancias políticas y financieras de cada reinado. Los diferentes trabajos realizados sobre esta cuestión coinciden en señalar una progresiva caída del peso de los tremises a partir del reinado de Chindasvinto que se acentuará notablemente con Wamba, llegando a su punto más bajo en el gobierno de Witiza donde la media se sitúa en los 1.115 gramos de peso ${ }^{41}$, existiendo numerosos ejemplares por debajo del gramo (PLIEGO 2009:II-44). Sin embargo, está disminución en el peso y la ley de las piezas parece ir acompañado de un incremento productivo que matizaría la visión tradicional del deterioro del sistema monetario visigodo a finales del siglo VII ${ }^{42}$. En el caso de los tremises que aquí

40 De hecho, algunos autores, al publicar ejemplares similares a los que aquí estudiamos, utilizan la expresión "trientes de plata”, que seguramente hace referencia al aspecto exterior de la pieza.

41 Peso medio del grupo tipológico con reverso de cruz sobre gradas obtenido por R. Pliego sobre 131 piezas (PLIEGO 2009:I-203, tabla 11). El general para el reinado dado por J. Vico, M.C. Cores y G. Cores (2006: 90) para 81 ejemplares es de 1.237 g.

42 Dicha visión tradicional se ha basado fundamentalmente en las dificultades económicas derivadas de las oleadas de plagas, pestes y malas cosechas, que afectaron al reino visigodo en sus últimas décadas (Véase una detallada descripción de las mismas y sus consecuencias en L. García Moreno, 1986), y en la evidente reducción en el peso y en la calidad del metal que presentan las monedas. Esta visión de crisis y decadencia que defiende el deterioro del sistema en los momentos finales del reino visigodo (véase R. Pliego, 2011) ha sido matizada por M. Castro (2010:290-291) y F. Retamero (2011:211) a partir de los porcentajes de producción, así como de los hallazgos monetarios y sus contextos. La ausencia o escasez en los hallazgos de esta época de moneda de periodos anteriores permite plantear, según M. Castro, "una intensa renovatio de la moneda mediante el fundido, y nueva acuñación del oro" (CASTRO, 2011:240). 
estudiamos se sitúan alrededor de un gramo de peso, salvo el ejemplar a nombre de Ervigio cuyo peso es de $1.40 \mathrm{~g}$.

\section{El contexto del oro: el área monumental religiosa}

Los seis tremises visigodos fueron hallados en la zona alta de la ciudad, en niveles de uso y derrumbe del ámbito del área religiosoadministrativa que conforman la basílica y el palatium, siempre por debajo de las construcciones del barrio islámico que se les superpone. La moneda más antigua, la acuñada en la ceca de Ispali bajo el reinado de Ervigio, se halló en el pórtico monumental situado en el extremo occidental del complejo, junto a la estancia norte del baptisterio (Figura 9, nº1). alejada de la de su deposición en el registro arqueológico, si tenemos en cuenta que el edificio palatino había perdido su uso en la segunda mitad del siglo VIII. Cabe mencionar que, en el estrato de colmatación que cubre dicho pavimento ${ }^{44}$, se halló una moneda constantiniana, mientras que, en el nivel de abandono que cubre a este último, se localizaron dos nummi del siglo IV d.C. La posición estratigráfica de estos cobres del siglo IV d. C. es significativa pues, sin llegar a los niveles del barrio islámico, es evidente que circularon con posterioridad a la fecha de emisión de la moneda de Ervigio.

Una segunda pieza, esta vez a nombre de Égica y Witiza (694/5-702), fue localizada en un lugar próximo a la anterior pero esta vez en un
Dicho pórtico, que cierra el espacio abierto que da acceso a la plaza porticada existente entre la basílica y el palatium, articula la fachada occidental del complejo, y señala la entrada simbólica al espacio sacralizado (GUTIÉRREZ Y CÁNOVAS 2009:124-125). La moneda fue hallada sobre el pavimento del mencionado pórtico ${ }^{43}$, pavimento que reformaba a otro anterior, en un momento en que el edificio visigodo se encontraba aún en uso. Su deposición sobre el mencionado pavimento posiblemente se debiera a una pérdida casual de la moneda y corrobora el uso del edificio en un momento muy avanzado del siglo VII. Este tremís debió tener una corta vida como circulante, dado que su fecha de acuñación, entre el año 680 y el 687 d.C., no debe estar muy

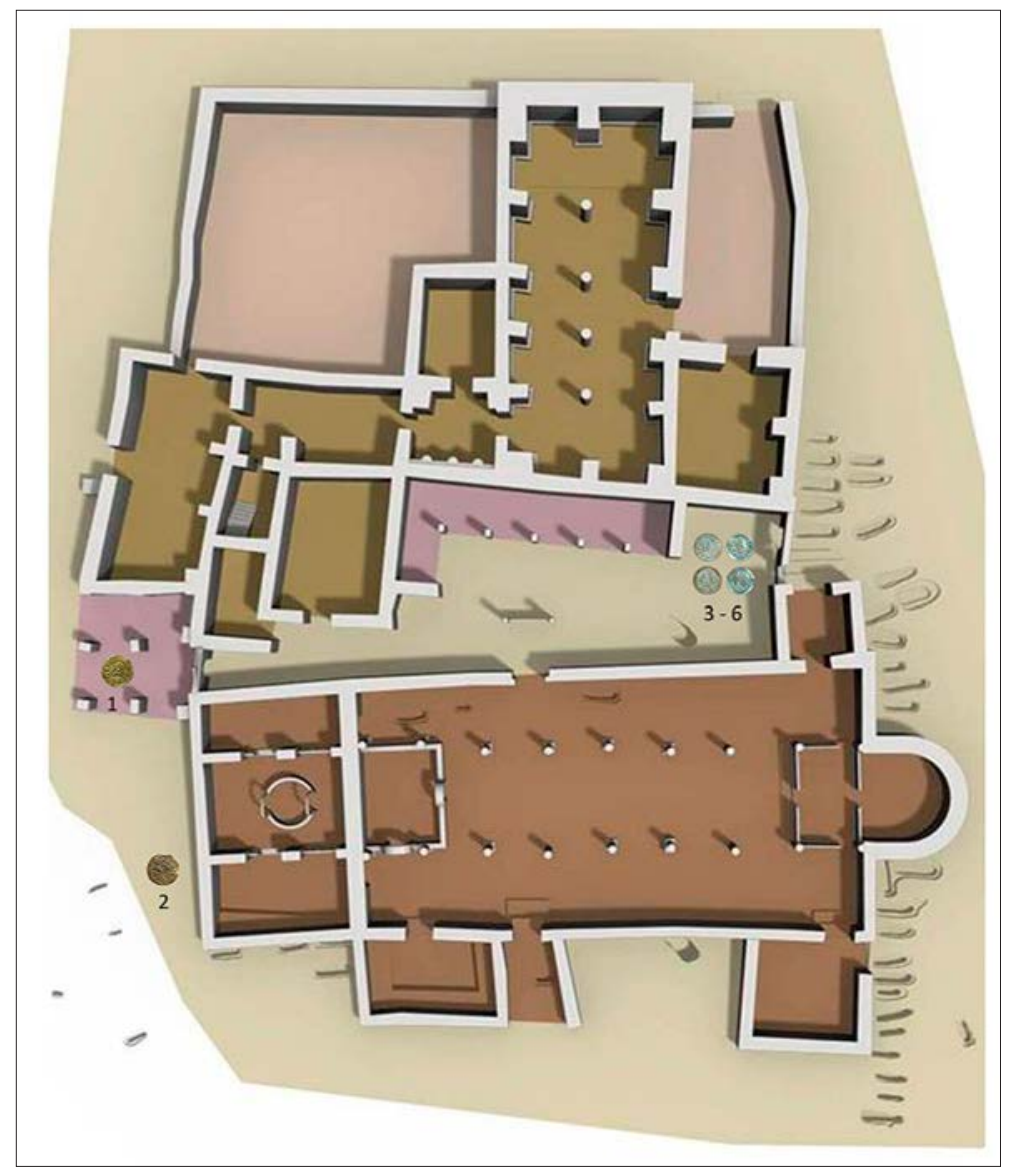

Fig. 9. Espacialización de los tremises hallados el complejo episcopal. 1: triente de Ervigio; 2: triente de Égica y Witiza; 3 a 6: trientes de Witiza. 
área exterior al palatium, junto al baptisterio de la basílica, pero fuera de él (Figura 9, n²) ${ }^{45}$. Se encontraba en un estrato de tierra anaranjada que se extiende por una amplia zona del complejo monumental y que "parece reflejar la voluntad de crear una repavimentación en aquellas estancias del palacio que tienden a reemplearse en este momento" (CAÑAVATE, MELLADO Y SARABIA, 2009:12). En la misma unidad estratigráfica fueron localizadas tres monedas romanas (dos nummi y un sestercio altoimperial) y una ibérica. La fecha de acuñación de este tremís, entre los últimos años del siglo VII o los primeros del VIII, obliga a situar su momento de uso en esta última centuria. Su posición estratigráfica, en un nivel de derrumbe del complejo episcopal, lo confirma.

Los cuatro tremises restantes, acuñados durante la primera década del siglo VIII bajo el reinado de Witiza en solitario (700-710), fueron exhumados en el mismo espacio (Figura 9, n०3-6) aunque no existe ninguna evidencia de que constituyesen una ocultación ${ }^{46}$. Se trata de una zona abierta situada entre el palatium y el muro norte de la basílica, junto a la entrada septentrional de la misma, en un contexto estratigráfico de destrucción posterior al abandono de ambos edificios (GUTIÉRREZ, GAMO y AMORÓS, 2003:138). El nivel de exhumación de estos tremises, al igual que el estrato donde fue hallado el de Égica y Witiza, fue cubierto por otros relacionados con la construcción del barrio islámico que se le superpone, lo que significa que su deposición en el registro arqueológico debió producirse en un momento indeterminado del siglo VIII.

Los seis tremises han sido hallados en espacios abiertos del complejo episcopal. Dicho complejo por su propia naturaleza (palacio, basílica y baptisterio) es claramente un espacio de poder y representación vinculado con grupos privilegiados. Su significado simbólico y social queda reforzado, tanto por la entidad de los restos exhumados, como por su ubicación en una posición central de la parte alta del cerro, desde donde sería visible desde cualquier punto de la ciudad (GUTIÉRREZ y CÁNOVAS, 2009:93). A esto, hay que añadir la información proporcionada por los registros cerámicos procedentes de esta zona del yacimiento que muestran que

\section{cada vez son más evidentes los indicios de consumo de ciertos productos de lejana procedencia, distribuidos en contenedo- res africanos y orientales -ánforas Keay LXI y LXII, ungüentarios tardíos y ciertos testimonios de recipientes atestiguados en Constantinopla-, en un repertorio de pro- ductos importados -es decir, de comercio- compartido con Recópolis, que nos habla del mantenimiento de un comercio selec- tivo, posiblemente reducido y puntual, relacionado con la demanda de productos específicos por parte de ciertos grupos sociales privilegiados - ¿vino, perfumes, aceite?- (GUTIÉRREZ Y CÁNOVAS, 2009: 125-6).}

Teniendo en cuenta este contexto material, el hallazgo de los seis tremises no debe resultar extraño y, conviene recordarlo, se trata de moneda que no fue ocultada, sino perdida en un momento en el que estaba siendo usada en el ámbito de un espacio de representación con funciones litúrgicas, administrativas y residenciales ligadas a la presencia de una autoridad eclesiástica. Es en estos lugares vinculados con los potentes donde estas monedas de oro -aunque de muy baja ley- debieron tener su espacio de circulación preferente. En este sentido resulta significativo que el área del complejo monumental de El Tolmo de Minateda haya proporcionado uno de los volúmenes más relevantes de moneda visigoda no atesorada ${ }^{47}$ hallados en contextos estratigráficos conocidos hasta el momento.

45 U.E. 63046.

46 La interpretación de estas cuatro piezas como un tesoro hecha por R. Pliego (2009:I-253) debe ser tomada con cautela.

47 La mayor parte de las piezas visigodas conocidas fueron halladas formando parte de conjuntos monetarios. Fuera de atesoramientos los hallazgos son escasos, lo que ha sido interpretado como evidencia de su escasa circulación. Véase R. Pliego (2009:I-230). 


\section{SOBRE EL USO DE LOS TREMISES EN ÉPOCA VISIGODA}

Tradicionalmente, los estudios numismáticos realizados sobre el reino visigodo se han centrado en la única moneda acuñada con seguridad por dicho Estado: el tremís de oro, sin considerar el papel que pudo jugar el numerario tardorromano en la dinámica circulatoria de dicho periodo ${ }^{48}$. Desde esta perspectiva, ajena a la presencia de unas antiguas monedas de bajo valor liberatorio que se mantenían en circulación, y dejando de lado por el momento las cuestionadas emisiones de cobres visigodos defendidas por M. Crusafont, se ha debatido en numerosas ocasiones el uso y función de los tremises visigodos en la economía del reino. En ese punto, aparece inevitablemente la cuestión de su alto valor intrínseco, que condiciona en gran medida su función como instrumento de intercambio. Fruto de este debate, se han propuesto diferentes y variadas interpretaciones ${ }^{49}$. Además de jugar un importante papel propagandístico ${ }^{50}$, su alto valor adquisitivo ha sugerido a algunos investigadores un uso limitado y vinculado a los círculos de poder, que lo utilizarían en la compra de productos de lujo. Sin embargo, el intento de relacionarlo con el comercio internacional en base a los hallazgos del norte de Europa ${ }^{51}$, parece poco posible a la luz de los conocimientos actuales sobre la regionalización de las redes comerciales que hacen difícilmente sostenible esta interpretación.

D.M. Metcalf (1988) insistió en el carácter comercial de los tremises visigodos que, aunque acuñados con fines administrativos y fiscales, jugarían un papel muy importante tanto en el comercio de productos de lujo a larga distancia ${ }^{52}$ como en los intercambios realizados a menor escala. Basándose en la dispersión de los hallazgos de monedas aisladas, consideró que esta debió ser usada ampliamente y propuso una economía altamente monetizada que explicaría el uso común de los tremises en ámbitos rurales. Esta interpretación ha sido seguida, entre otros, por P. de Palol (1986 y 1999) en su análisis de los hallazgos de El Bovalar. El elevado número de cuños detectados vendría, según él, a reforzar esta hipótesis, considerando que los números cuños utilizados indicarían un alto volumen de acuñación ${ }^{53}$.

Otro posible uso que se ha propuesto para las emisiones de tremises es el de servir de pagos a las tropas, vinculando así las emisiones con campañas militares ${ }^{54}$. Se trataría pues de amonedaciones realizadas en cecas itinerantes que cambiarían de lugar en función de las necesidades bélicas. Este argumento se ha utilizado frecuentemente para explicar las emisiones irregulares de las numerosas cecas del noroeste peninsular, pero ha sido contestado por algunos autores como A. Marques de Faria (1988) quien, en base a los hallazgos aislados de cada uno de los reinados, defendía que estas emisiones no se podían relacionar con las campañas militares; $y$, posteriormente, por P. Díaz (2004) quien vincula los talleres de acuñación con la red parroquial recogida por el Parrochiale Suevum, y, por tanto, con una organización administrativa y no militar.

\footnotetext{
48 Véase nota 27.

49 Sin pretender profundizar en ellas, esbozamos en las líneas que siguen las principales hipótesis sobre función de la moneda visigoda. Un análisis más extenso puede verse en R. Pliego (2009:I-221 y ss.).

50 El uso del numerario como medio de propaganda política ha sido habitual a lo largo de la historia. Para el periodo que nos ocupa es especialmente evidente en algunos episodios como las luchas político-religiosas protagonizadas por Leovigildo y Hermenegildo. Véase J.N. Hillgarth (1966) y, más recientemente, R. Pliego (2009:I-86). Para el último periodo visigodo véase R. Pliego (2011).

51 Esta interpretación, formulada entre otros por J. Orlandis, se basa en los hallazgos de tremises en lugares como el norte de Francia, Bélgica, Países Bajos, región del Rin o sur de Inglaterra hasta finales del siglo VI. El propio autor matiza la importancia relativa que debió tener este comercio exterior, lo que le lleva a afirmar que "la moneda de oro parece haber servido más para fines de atesoramiento por parte del fisco y los potentes que como normal instrumento de los intercambios” (ORLANDIS, 1977:203).

52 Según L. García Moreno (1975:109) en manos de agentes orientales y destinado a una minoría.

53 Esta consideración ha sido discutida por F. Retamero (2001 y 2011), siguiendo a M. Barceló (1999) y los trabajos de T. Buttrey (1993 y 1994), argumentando que un número elevado de cuños no tiene porqué significar una acuñación masiva.

54 Se trata de una interpretación formulada desde antiguo entre otros por O. Gil Farrés (1955) y A. Barbero y M. Vigil (1970, 1974 y 1978).
} 
Una de las hipótesis más defendidas ha sido la que considera que estas amonedaciones serían esencialmente una herramienta fiscal, reduciendo la función del oro acuñado a un mero uso tributario. Esta hipótesis ha sido defendida entre otros por M.F. Hendy, (1988), M. Barceló (1981) y F. Retamero (1999, 2001) y, más recientemente, ampliamente tratada por I. Martín (2006, 2008 a y b, 2011, 2013) en base a los hallazgos de moneda en el ámbito lusitano en centros de poder y el estudio de los textos en pizarra. Este autor ha desarrollado ampliamente la hipótesis fiscal. En su opinión, la moneda es básicamente un instrumento fiscal y las acuñaciones visigodas responden a la necesidad del Estado de recaudar en oro. La presencia de moneda en áreas rurales estaría relacionada con la captación tributaria ya que los pagos realizados en especie debían ser convertidos en moneda. La necesidad de transformar dicha recaudación en moneda explicaría la acuñación de tremises. Así, las emisiones de tremises en una ceca como Salmantica durante los reinados de Recaredo, Witerico, Suintila, Ervigio y Égica, datarían la captación de tributos en los territorios de la diócesis salmantina (MARTín, 2006). En el proceso recaudatorio los obispos jugarían un importante papel como agentes fiscales ya que serían los encargados de capturar los excedentes in situ, negociar con los numerarii el valor de la adaeratio ${ }^{55}$ y hacer efectivo el pago del tributo en sus territorios episcopales (MARTín, 2013:76). Aunque los prelados no serían los únicos potentes locales vinculados a esta actividad tributaria en su doble función de agentes y sujetos fiscales, sino que también podía ser realizada por poderes laicos locales, parece que jugaron un importante papel fiscal que se añadía a sus numerosas prerrogativas judiciales y políticas. De esta forma, los centros de culto episcopales se convirtieron en auténticos espacios de poder y sustituyeron a los antiguos espacios públicos (MARTín, 2006:284 y 2013).

Para R. Pliego el objetivo primordial de la producción de tremises habría sido la redistribución estatal que se realizaría a través del pago de rescates, regalos, dotes, donaciones, etc. Así, la moneda habría servido fundamentalmente para el pago y cobro de servicios acorde con la estructura de un Estado como el visigodo, con un poder monárquico débil que necesitaba comprar y premiar fidelidades de unas élites que no siempre le eran favorables (PLIEGO, 2009:I-229-230). La consideración de la moneda visigoda ante todo como "un instrumento de regulación política" ha sido destacada por F. Retamero, para quien "la moneda fue el instrumento principal de relación política entre el rex y los potentes", del que derivarían otros usos como el fiscal y el comercial (RETAMERO, 2011:208).

En el marco de este debate, la contextualización de los hallazgos aislados puede aportar algunos indicios que arrojen algo de luz sobre esta cuestión. El problema es que en pocos casos se tiene información sobre el lugar exacto del que proceden los hallazgos y en menor medida sobre el carácter de los espacios donde se han localizado las monedas. Todavía son muy escasos los tremises recuperados en el curso de trabajos arqueológicos que permitan aportar información a este respecto ${ }^{56}$. Esta circunstancia obliga necesariamente a la prudencia ya que, en el estado actual de la investigación, no es posible obtener resultados definitivos, no obstante, algunos de los casos conocidos aportan indicios de considerable interés.

De entre los hallazgos conocidos existen algunos vinculados a edificios religiosos como es el caso de los tremises de El Tolmo de Mina-

\footnotetext{
55 Mecanismo fiscal del bajo Imperio romano consistente en la conversión en moneda del tributo pagado en especie, y mencionado en el documento conocido como De fisco barcinonensi, epístola agregada a los cánones del I Concilio de Barcelona del año 592 (MARTín VISO, 2013:76). Dicho texto evidencia su pervivencia a finales del siglo VI aunque, en opinión de R. Pliego (2009:I-224) eso no significa necesariamente que esta práctica pueda hacerse extensiva a todos los territorios peninsulares ni a todo el periodo.

56 Desde la clásica obra de X. Barral (1976) hasta la actualidad, el corpus de hallazgos contextualizados arqueológicamente sigue siendo muy reducido. Una actualización de los tesoros en R. Pliego (2009: I-231 y ss.) y en general (2009-Il y 2012). Para los hallazgos de tremises en contextos arqueológicos de la Carthaginensis y en el centro peninsular véase M. Castro (2010 y 2011 ).
} 
teda que nos ocupa, un tremís de Recesvinto hallado en las excavaciones de la iglesia de Idanha-a-Vella en un lugar donde se identificó un supuesto palacio episcopal, o el de Chindasvinto localizado en el episcopio de Ávila de los Caballeros (MARTín VISO, 2008 a: 180). Pero Junto a estos ejemplos, contamos también con otros localizados fuera de dichos ambientes. El tremís a nombre de Tulga encontrado en una zona comercial de Recópolis, o el de Leovigildo, hallado en una zona de viviendas próximas al área productiva y comercial, no plantearían mayores problemas, tanto por el hecho de hallarse en la propia ciudad palatina como por haber sido localizados en un área con evidentes vestigios de actividad comercial o próximo a ella (CASTRO, 2010:292) ${ }^{57}$.

Más difíciles de explicar con una visión exclusivamente fiscal del uso del tremís son los ejemplos vinculados a poblados fortificados de campesinos, agricultores, ganaderos y pescadores como sucede en Puig Room donde fue hallado un tremís de Akhila de la ceca de Gerona (PALOL, 1952:177), o los encontrados en ambientes domésticos como el tremís en el asentamiento rural de La Vega (Boadilla del Monte, Madrid) aparecido en el estrato de derrumbe de una estancia de características constructivas iguales al el resto de las estancias habitacionales (ALFARO y MARTín, 2000: 226; 2007 y VIGIL, 2011).

De ámbito doméstico pero en contexto urbano es el conjunto localizado en las excavaciones del foro de Mérida. Se trata de una ocultación de veinte tremises a nombre de Leovigildo que se hallaron bajo un muro de una casa visigoda que fue construida aprovechando la pared del templo romano (MATEOS, PIZZO y PLIEGO, 2005:259). No es fácil interpretar una ocultación de tal envergadura en un espacio doméstico cuya sencillez denota condición humilde, según sus excavadores, quienes lo explican relacionándolo con "la figura del obispo Masona y su afamada generosidad para con los pobres así como las tensiones entre católicos y arrianos, con los intentos de compra de la voluntad de los primeros, el pulso mantenido entre autoridades eclesiásticas de uno y otro signo y la participación activa del rey Leovigildo en el conflicto" (ALBA Y MATEOS, 2006:371).

El ejemplo de El Bovalar es también relevante porque, aunque el lugar cuenta con una basílica, los veinte tremises localizados en el asentamiento hasta el momento, han sido hallados en el interior de casas "en un ambiente familiar, junto a broches de cinturón y otros objetos de uso diario", interpretándose como las monedas que tenían en propiedad algunos habitantes del poblado en el momento del incendio que lo destruyó (PALOL, 1986:517 y 1999:343). Recientemente se ha propuesto otra interpretación formulada por J.M. Gurt quien, recogiendo una idea ya mencionada por E. Ariño y P.C. Díaz, planteaba la existencia de una comunidad monástica en El Bovalar coincidente con la segunda fase de la basílica. Dicha comunidad monástica acomodada explicaría la existencia de los materiales encontrados en la iglesia y la presencia de moneda (GURT, 2007:211).

Los hallazgos numismáticos acaecidos en los últimos años evidencian también la existencia de una cantidad importante de moneda en contextos urbanos. Estos hallazgos sugieren un cambio en cuanto a los ámbitos de distribución de los mismos respecto al panorama que se conocía con anterioridad. En su estudio sobre la circulación de monedas suevas y visigodas realizado hace ya más de tres décadas a partir de las monedas conocidas en ese momento, X. Barral (1976:164) llegaba a la conclusión de que solo un mínimo porcentaje de piezas se localizaban en medios urbanos, mientras que eran muy abundantes en zonas rurales. Algunos hallazgos realizados en el marco de excavaciones arqueológicas como los ya mencionados del foro de Méri-

\footnotetext{
57 La moneda de Leovigildo se halló en un estrato datado en el segundo tercio del siglo VII, mientras que la de Tulga corresponde a un momento avanzado del siglo VIII (CASTRO, 2011:239).
} 
da, Recópolis ${ }^{58}$ o La Vega Baja de Toledo ${ }^{59}$, y los del propio Tolmo de Minateda, permiten matizar dicha afirmación, toda vez que ponen de manifiesto la importancia de las ciudades en la dinámica monetaria del reino visigodo. Este cambio de perspectiva parece ser especialmente significativo en el centro peninsular donde, según M. Castro (2011:226), la moneda se distribuye predominantemente en los centros urbanos, en detrimento de los ámbitos rurales, donde está ausente o es poco frecuente. Este predominio, que no se da en otras áreas, como la zona Noreste de la Lusitania, donde los tremises se encuentran, además de en las civitates, en algunos lugares en altura vinculados con poderes locales laicos y algunos centros religiosos ${ }^{60}$, se muestra con claridad en los territorios de la antigua provincia Carthaginensis ${ }^{61}$ donde los datos arqueológicos, según este autor, permiten sostener que las civitates son "las receptoras y transformadoras de la circulación monetaria, como nodos centrales del poder de la organización política del regnum visigothorum" (CASTRO, 2011:226), convirtiéndose en verdaderos centros redistribuidores del sistema fiscal. En este sentido, es conveniente recordar el papel de las ciudades en dicho proceso fiscal como centros de captación y redistribución de renta ${ }^{62}$. Las ciudades son, por tanto, importantes centros de poder, fundamentales en el entramado tributario, y el escenario propicio para la circulación de moneda.

\section{CONCLUSIONES}

Los trabajos de excavaciones sistemáticas llevadas a cabo en El Tolmo de Minateda (Hellín, Albacete) han permitido exhumar diferentes espacios de una civitas visigoda creada ex novo a finales del siglo $\mathrm{VI}$ o inicios del VII sobre las ruinas de un antiguo municipium romano. Los materiales numismáticos recuperados en el marco de dichos trabajos constituyen una muestra del circulante de la ciudad y permiten vislumbrar la dinámica monetaria de esta urbe a partir de su análisis en el marco del contexto estratigráfico en el que aparecen.

Es esta contextualización estratigráfica de los hallazgos monetarios la que ha permitido evidenciar que la moneda circuló de forma habitual por la ciudad visigoda de El Tolmo de Minateda, y que este circulante, no sólo estaba formado por tremises, que se encuentran en escaso número por su alto valor, sino que mayoritariamente lo componen monedas romanas. Se trataba en su mayor parte de las viejas monedas romanas, fundamentalmente de cronología bajoimperial, que se debieron utilizar sin ningún problema que pudiera derivar de la autoridad emisora. Esta moneda aparece en distintos ambientes (domésticos, defensivos, de vertidos o de poder) y debió mantener la función de instrumento de cambio que había tenido en época romana. Su frecuencia y dispersión en los distintos ámbitos del yacimiento parece indicar que no estamos ante un fenómeno de residualidad de unas pocas monedas de periodos anteriores, sino más bien de material numismático romano que forma parte del circulante habitual de la ciudad. Dicho material, mayoritariamente acuñado en los siglos III y IV d.C., debió llegar al asentamiento visigodo con posterioridad a partir de finales del siglo $\mathrm{VI}$ o inicios de la centuria siguiente, cuando se refunda la civitas, dado que, según los datos arqueológicos obtenidos hasta el momento, cuando se emitieron estos cobres el asentamiento no

58 Una relación completa de los hallazgos de esta ciudad y sus contextos en M. Castro (2005 y 2008).

59 R. Caballero, B. Maquedano y E.I. Sánchez (2010).

60 Véase I. Martín (2008 a y b).

61 Las diferencias entre las distintas áreas peninsulares analizadas por M. Castro a partir de criterios productivos, organización de las cecas y la evidencia de los hallazgos han permitido a este autor establecer distintos modelos regionales que utilizan patrones organizativos y de acuñación diferentes. Un análisis de dichos modelos en M. Castro (2010 y 2011).

62 El papel de las ciudades en el sistema tributario visigodo ha sido destacado recientemente, entre otros, por I. Martín (2008 a y 2013) y M. Castro (2010 y 2011). 
parece estar habitado. El análisis estratigráfico de estos materiales numismáticos sugiere un uso indiscriminado de todo el circulante anterior, incluso de aquellas monedas residuales acuñadas con anterioridad al cambio de era, que eran ya bastante escasas en esos momentos, pero que debió servir para los intercambios menores en un momento en el que la producción de este tipo de numerario era inexistente ${ }^{63}$.

En este sentido, el análisis de este enclave $y$ de algunos otros ya mencionados ${ }^{64}$ pone de manifiesto la necesidad de abordar los estudios sobre el grado de monetización y el uso de la moneda en la sociedad visigoda teniendo en cuenta la presencia de un numerario romano, que no solo puede ser abundante sino también mayoritario. Un análisis basado exclusivamente en las emisiones de tremises puede conducir a graves errores de interpretación tanto en lo que se refiere a la mayor o menor presencia y uso de moneda, como en lo concerniente al papel jugado por la misma en la sociedad visigoda.

En el caso del oro son de nuevo los contextos los que permiten aproximarnos a su ámbito de uso. La información derivada de la contextualización espacial de algunos hallazgos de tremises evidencia su vinculación con los centros de poder. La presencia de estos tremises en ámbitos urbanos u otros espacios relacionados con los poderes laicos o eclesiásticos, incide en la hipótesis de su uso como instrumento recaudatorio por parte del fisco.
El caso de El Tolmo es un buen ejemplo en ese sentido, puesto que los seis tremises recuperados han sido exhumados, además de en un ámbito urbano, en el espacio ocupado por el conjunto monumental de carácter litúrgico, administrativo y residencial formado por la basílica, el baptisterio y el palatium. El carácter episcopal de esta civitas visigoda, creada ex novo con la finalidad de ser la cabeza de un nuevo obispado, incide directamente en el activo papel de los prelados en el proceso tributario 65.

Pero dicho uso fiscal no tuvo porque ser ni único ni excluir otros usos que son intrínsecos a la moneda. Si como parece la sociedad visigoda no fue ajena el uso de numerario (tanto el acuñado por el propio Estado como el que se mantiene en circulación de periodos anteriores), se podría plantear que los tremises también pudieran usarse ocasionalmente para otros fines diferentes al de la mera recaudación fiscal, aunque esos otros usos fueran limitados y restringidos a ciertos sectores de la sociedad, dado su alto poder liberatorio. Así parecen demostrarlo hallazgos como los de Puig Room o La Vega procedentes de ámbitos sin ninguna relación aparente con espacios de poder.

Sin embargo, son los lugares relacionados con las élites y los grupos sociales privilegiados donde se han localizado los mayores volúmenes de moneda no atesorada. Es el caso de las civitates, como evidencian los hallazgos procedentes de contextos urbanos

63 En los últimos años se ha insistido en la posibilidad de que los llamados cobres visigodos por M. Crusafont (1984, 1988, 1990, 1994 y 1998) fueran acuñados durante el Reino de Toledo para ser usados en los pequeños intercambios. Sin embargo, aun aceptando su carácter hispano y su coincidencia cronológica con la etapa visigoda, no parecen ser emisiones oficiales del Estado, dadas sus divergencias con las emisiones áureas. La problemática respecto a quien realiza o autoriza estas emisiones está por dilucidar. Véase R. Pliego (2009:I-189-190).

64 Son especialmente significativos los casos de Recópolis y La Vega Baja de Toledo cuyos hallazgos monetarios han sido dados a conocer por M. Castro (2005 y 2008) y R. Caballero, B. Maquedano y E.I. Sánchez (2010) respectivamente.

65 La cuestión de la participación de los obispos en el proceso tributario como agentes fiscales ha sido tratado por diversos autores. Un trabajo reciente es el de I. Martín Viso quien, siguiendo a M. Barceló y F. Retamero, defiende el protagonismo de los obispados como centros organizativos de la tributación de forma que "los núcleos de poder episcopales -y con ellos los centros de cultosustituyeron a los antiguos espacios públicos" (MARTín VISO, 2006:284). Para este autor los obispos "son los que acuerdan fijar el valor del modio canónico, una media que imponen a los encargados de ejecutar la recaudación, los numerarii, ... se encargarían de hacer efectivo el pago de los tributos en sus territorios episcopales, ... desempeñaban una labor de conexión entre el poder central y los productores que aportaban el excedente, situándose así como auténticas bisagras, sin cuya colaboración no es posible recaudar nada" (MARTÍN VISO, 2013:76). En contra de esta opinión, D. Fernández (2006) reducen la función de los obispos en el proceso de recaudación de impuestos, a simples portavoces de las comunidades locales y de sus élites. 
anteriormente mencionados, y también de algunos centros de carácter religioso como El Bovalar, de confirmarse su interpretación como monasterio y, por tanto, lugar de recaudación fiscal y de renta. Según J.M. Gurt, el numerario de este enclave, "dado el registro arqueológico que presentaba, podemos pensar que se trata más de moneda en circulación y repartida, que no acumulada y perteneciente a una sola tesaurización" (GURT, 2007: 211).

En El Tolmo de Minateda aquí analizado, donde el ámbito urbano inherente al yacimiento se suma a su condición de sede episcopal, el carácter disperso de los hallazgos y la ausencia de indicios de ocultación o atesoramiento es aún más evidente. En ambos enclaves, El Bovalar y El Tolmo de Minateda, los tremises hallados corresponden a la última etapa del periodo visigodo, como también ocurre en La Vega y en Puig Room. Y, en ambos casos, la contextualización espacial y estratigráfica de estos hallazgos ha resultado fundamental a la hora de interpretarlos. La presencia de moneda de oro se une a la existencia en el mismo ámbito a objetos importados y a materiales que evidencian la presencia y el consumo de productos de procedencias lejanas que debieron estar al alcance de reducidos grupos privilegiados. Estos objetos, junto con las monedas y los restos arquitectónicos, proporcionan la impronta, deteriorada por el tiempo, de los modos de vida de una élite en una civitas episcopal a finales del reino visigodo.

\section{CATÁLOGO}

\section{Ervigio (680-687). Ispali.}

Anv:: Busto coronado del rey a la derecha, sujetando cruz con el brazo levantado.

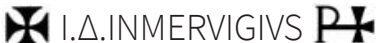

Rev.: Cruz griega sobre gradas (2 puntos debajo y uno a cada lado)

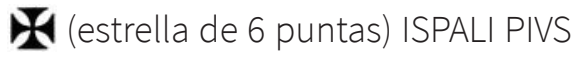

P.: 1.40 g. Mód.: 20 mm. P.C.:12

Ref. bibl.66: CNV 492 /RPV 648 a / MILES 408

No Reg.: Museo de Albacete 16306.

No.Inv.: 04/63345-1

\section{Égica - Witiza (694/5-702). Cesaraugusta.}

Anv.: Cetro crucífero entre dos bustos afrontados

\section{ADNNE.GICA P廿}

Rev:: Monograma del nombre de la ceca con "S" retrógrada

$$
\text { WVITTIZ.A.P廿(palma) }
$$

P.: 1.10 g. Mód.: 19 mm. P.C.: 6

Ref. bibl.: CNV 587.14 /RPV 718 p 67

No Reg.: Museo de Albacete 16307.

No.Inv.: 03/63046-1

66 Se utilizan las siguientes referencias bibliográficas: CNV (=VICO MONTEOLIVA, Jesús; CORES GORMENDIO,María Cruz y CORES URÍA, Gonzalo (2006): Corpus Nummorum Visigothorum. Ca.575-714 Leovigildus-Achila, Madrid.); RPV (=PLIEGO VÁZQUEZ, Ruth (2009): La moneda visigoda, 2 vols. Universidad de Sevilla. Sevilla.); y MILES (=MILES, G.C., 1952: The Coinage of the Visigoths of Spain. Leovigild to Achila II. New York).

67 Debemos hacer notar que en este último catálogo, la transcripción de la leyenda de reverso esta pieza contiene por error una doble "A" al final del nombre de Witiza. 


\section{Witiza (700-710). Córdoba.}

Anv.: Busto de perfil

I.N.D.IMNEWITTIZA

Rev.: Cruz griega sobre gradas

(3 puntos debajo)

\section{CORDOBA PATRICIA}

P.: 1.0 g. Mód.: 20.8 mm. P.C.: 6

Ref. bibl.: CNV 593.6 / RPV 777 i / MILES 504.

No Reg.: Museo de Albacete 15790.

No.Inv.: 01/61838-1

\section{Witiza (700-710). Tucci}

Anv.: Busto frontal

\section{E VITTIZAP}

Rev.: Cruz griega sobre gradas (punto entre la primera y la segunda grada)

W TVCCI PIVS (S en posición horizontal)

P.: 1.1 g. Mód.: 20.9 mm. P.C.: 6

Ref. bibl.: CNV 599.1/RPV 783 b

No Reg.: Museo de Albacete 15791.

No.Inv.: 01/61838-3

\section{Witiza (700-710). Tuccus.}

Anv.: Busto de perfil

$$
\text { IND[...]N.MEVITTIZA P }{ }^{69}
$$

Rev.: Cruz griega sobre gradas

(3 puntos debajo)

丞INDINME TUCCVS

P.: 1.0 g. Mód.: 20.5 mm. P.C.: 6

Ref. bibl.: CNV 601 /RPV 784 a

No Reg.: Museo de Albacete 15789.

No.Inv.: 01/61838-4

68 En la transcripción de la leyenda del anverso de ambos catálogos figura por error VITZ en lugar de WITTIZ. La "A" final del nombre que aparece en el CNV parece haberse transformado y funcionar como la "R" del nexo P

69 La cruz del nexo P¥ funciona aquí también como cruz de inicio. Sobre esta cuestión véase CNV, pág.567 nota 249. 


\section{BIBLIOGRAFÍA}

ABAD CASAL, Lorenzo (1996): "La epigrafía del Tolmo de Minateda (Hellín, Albacete) y un nuevo municipio romano del Conventus Carthaginensis", Archivo Español de Arqueología. 69. 77-108.

ABAD CASAL, Lorenzo; GUTIÉRREZ LLORET, Sonia; GAMO PARRAS, Blanca; y CÁNOVAS GUILLÉN, Pablo, (2008): "Una ciudad en el camino: pasado y futuro de El Tolmo de Minateda (Hellín, Albacete)" Zona Arqueológica 9, (Recópolis y la ciudad en la época visigoda). 322-337.

ABAD CASAL, Lorenzo y GUTIÉRREZ LLORET, Sonia (1997): "Iyih (El Tolmo de Minateda, Hellín, Albacete). Una civitas en el limes visigodo-bizantino" Antigüedad y Cristianismo XIV. 591-600.

ABAD CASAL, L.; GUTIÉRREZ LLORET, S.; GAMO PARRAS, B. 2000 a: "La ciudad visigoda del Tolmo de Minateda (Hellín, Albacete) y la sede episcopal de Eio", Los orígenes del cristianismo en Valencia y su entorno (Grandes Temas Arqueológicos II). Valencia. 101-112.

ABAD CASAL, L.; GUTIÉRREZ LLORET, S.; GAMO PARRAS, B. 2000 b: "La basílica y el baptisterio del Tolmo de Minateda (Hellín, Albacete)", Archivo Español de Arqueología. 73. 193-221.

ABAD CASAL, L.; GUTIÉRREZ LLORET, S., GAMO PARRAS, B. y CÁNOVAS GUILLEN, P. (2012): "El Tolmo de Minateda (Hellín, Albacete, España): un proyecto de investigación y puesta en valor del patrimonio". Debates de Arqueología Medieval. N. 2 (nov. 2012), 351-381. http://www. arqueologiamedievaldebates.com/articulo-46/el-tolmode-minateda-(hellin-albacete-espana):-un-proyecto-deinvestigacion-y-puesta-en-valor-del-patrimonio

ABAD CASAL, Lorenzo; GUTIÉRREZ LLORET, Sonia y SANZ GAMO, Rubí (1998): El Tolmo de Minateda. Una historia de tres mil quinientos años. Toledo, Junta de Comunidades de Castilla-La Mancha.

ALBA CALZADO, Migel y MATEOS CRUZ, Pedro (2006): "Transformación y ocupación tardoantigua y altomedieval del llamado Foro Provincial, en El "foro provincial" de Augusta Emerita: un conjunto monumental de culto imperial", Anejos de Archivo Español de Arqueología. XLII. 355-380.

ALFARO ARREGUI, Mar y MARTíN BAÑÓN, Asunción, (1999-2000): "La vega, asentamiento visigodo en Boadilla del Monte (Madrid)", E. Ruano (coord.): La arqueología madrileña en el final del siglo XX: desde la Prehistoria hasta el año 2000, Boletín de la Asociación Española de Amigos de la Arqueología. 39-40. 225-237.

ALFARO ARREGUI, M. y MARTíN BAÑÓN, A. (2007): "La Vega: un modelo de asentamiento rural visigodo en la provincia de Madrid", en J. Morín (ed.): La investigación arqueológica de la época visigoda en la Comunidad de Madrid, Zona Arqueológica. 8, Vol. II. Alcalá de Henares. 402-17.

AMORÓS RUIZ, V. (2012): Contextos cerámicos del siglo VIII en el Tolmo de Minateda. Instituto de Estudios Albacetense "Don Juan Manuel". Albacete.
AMORÓS RUIZ, Victoria; CAÑAVATE CASTEJON, Víctor; GUTIÉRREZ LLORET, Sonia; SARABIA BAUTISTA, Julia (2012) - Cerámica altomedieval en el Tolmo de Minateda (Hellín, Albacete, España). En Gelichi, Sauro (ed.) Atti del IX Congresso Internazionale sulla Ceramica Medievale nel Mediterraneo. Venezia 2009. Venezia: Edizioni All'Insegna del Giglio. 246-257.

ARIÑO GIL, Enrique y DÍAZ, P.C. (2003): "Poblamiento y organización del espacio: la Tarraconense pirenaica en el siglo Vl”, Antiquité Tardive. 11. 223-237.

BARBERO, A. \& VIGIL, M. (1970): "Algunos aspectos de la feudalización del reino visigodo, en relación con la organización financiera y militar", Moneda y Crédito. 112.71-91.

BARBERO, A. \& VIGIL, M. (1974): Sobre los orígenes sociales de la reconquista. Barcelona.

BARBERO, A. \& VIGIL, M. (1978): La formación del feudalismo en la península Ibérica. Barcelona.

BARCELÓ PERELLÓ, Miquel (1981): "A statistical approach to multiple mint issues of royal coinage, the case of the Visigoths in Hispania (585-711)", Statistics and Numismatics. París. 138-154.

BARCELÓ PERELLÓ, Miquel (1999): "De fisco gotico, hispanico sive andalusico”, Faventia. 21. 103-118.

BARRAL I ALTET, Xavier (1976): La circulations des monnaies suèves et visigotiques, contribution à l'histoire économique du royaume visigot, Zürich-München.

BARTLETT, P.; CORES URÍA, G. y CORES GOMENDIO, M.C. (2005): "The use of dots as control marks in the coin legends at the visigothic mint of Ispali during the reign of Sisebut (612-621)", Actas del XIII Congreso Internacional de Numismática (septiembre 2003). Madrid, t.Il. 1127-1134.

BUTTREY, T.V. (1993):"Calculating Ancient Coin Production: Facts and Fantasies," Numismatic Chronicle. 153. 335-351.

BUTTREY, T.V. (1994):"Calculating Ancient Coin Production II: Why it cannot be done," Numismatic Chronicle. 154. 341-352.

CABALLERO GARCÍA, Rafael, MAQUEDANO CARRASCO, Bienvenido y SÁNCHEZ PELÁEZ, Elena Isabel (2010): El oro de los visigodos. Tesoros numismáticos de la Vega Baja de Toledo. Serie Arqueología y Patrimonio 2. La Ergástula ediciones. Madrid.

CÁNOVAS GUILLÉN Pablo, CAÑAVATE, Víctor y SARABIA, Julia (2010): Una ciudad recuperada. Estudio arqueológico y etnográfico de una casa semirrupestre en el Tolmo de Minateda. Instituto de estudios albacetenses "Don Juan Manuel", Serie I-Estudios, Albacete.

CAÑAVATE CASTEJÓN, V.; MELLADO RIVERA, J.A. y SARABIA BAUTISTA, J. (2009): "Uso, residualidad y problemática del siglo VIII en el palacio de época visigoda del Tolmo de Minateda (Hellín, Albacete)", Arqueología y Territorio Medieval. 16. 9-31.

CASTRO PRIEGO, Manuel (2005): "Arqueología y Numismática: los hallazgos de época visigoda de La Vega (Madrid) y Recópolis (Guadalajara)", XIII Congreso Nacional de Numismática, vol.2. Madrid. 1165-1171. 
CASTRO PRIEGO, Manuel (2008): "Los hallazgos numismáticos de Recópolis: aspectos singulares de su integración en la secuencia histórica del yacimiento", Zona arqueológica 9: Recópolis y la ciudad en época visigoda. 130-141.

CASTRO PRIEGO, Manuel (2010): "El sistema monetario visigodo y su alcance regional: el ejemplo de la provincia Carthaginensis y la ceca de Toledo", García, A., Olmo, L., Izquierdo, R., Peris, D. (eds.), Espacios urbanos en el Occidente Mediterráneo (s. VI-VIII), Ciudad Real. 2010. 285-294.

CASTRO PRIEGO, Manuel (2011): "La circulación monetaria de los s. VII-VIII en la Península Ibérica: un modelo en crisis", Zona Arqueológica 15-II. Madrid. 225-242.

CHAVES FERNÁNDEZ, Rafael y CHAVES GÓMEZ, Ma José (1985): "Un triente visigodo de Witiza (698-710) de ceca TV..., inédito”, Gaceta Numismática. 76. 39-41.

CHAVES FERNÁNDEZ, Rafael y CHAVES GÓMEZ, Ma José (1991-1993): "La moneda visigoda", Acta Numismática. 21-23. 331-336.

CORREA RODRÍGUEZ, José Antonio (2006): "El latín de las monedas visigodas", en C. Arias Abellán (ed.) Latin vulgaire-latin tardif. Actes du VIlème Colloque International sur le latin vulgaire et tardif (Sevilla 2-6 de septiembre de 2003), Sevilla. 219-241.

CRUSAFONT I SABATER, Miquel (1984): “ ¿Un numerario visigodo de cobre? Gaceta Numismática. 74-75. 131-141.

CRUSAFONT I SABATER, Miquel (1988): "The copper coinage of the Visigoths of Spain" Problems of medieval coinage in the Iberian Area 3, pp. 35-70.

CRUSAFONT I SABATER, Miquel (1990): "The copper coinage of the Visigoths of Spain: new evidence" Spink Numismatic Circular vol. XCVIII, no 9, november.

CRUSAFONT I SABATER, Miquel (1994): El sistema monetario visigodo: cobre y oro, Barcelona-Madrid.

CRUSAFONT I SABATER, Miquel (1998): "Nuevos datos sobre cobres visigodos" IV Congreso Nacional de Numismática, Lisboa. 125-144.

DÍAZ, P.C. 2004: "Acuñación monetaria y organización administrativa en la Gallaecia tardoantigua", Zephyrus. 57. 367-375.

DOMÉNECH BELDA, Carolina (2009): "La moneda de excavación y sus aportaciones” en A. Arévalo (eds.), XIII Congreso Nacional de Numismática, Cádiz (22-24 octubre 2007), 707-736.

DOMÉNECH BELDA, Carolina (2013): "La circulation de monnaie carolingienne à la péninsule Ibérique. À propos de un denier de l'atelier de Roda", Revue Numismatique. 170. 383-410.

DOMÉNECH BELDA, Carolina y GUTIÉRREZ LLORET, Sonia (2005): "Las monedas de El Tolmo de Minateda, Hellín (Albacete)", XIII Congreso Internacional de Numismática (Madrid, 2003). Madrid. 1567-1576.
DOMÉNECH BELDA, Carolina y GUTIÉRREZ LLORET, Sonia (2006): "Viejas y nuevas monedas en la ciudad emiral de Madinat lyyuh (El Tolmo de MInateda, Hellín, Albacete)", Al-Qantara. XXVII, n². 337-374.

FERNÁNDEZ, Damián (2006): "What is the Fisco Barcinonensi about?", Antiquité Tardive. 14. 217-224.

FRANCISCO OLMOS, José María de (2009): "El Morbo Gothico. La moneda como fuente de estudio de la sucesión al trono en la monarquía visigoda", VIII Jornadas Científicas sobre Documentación de la Hispania Altomedieval (siglos VI-X). Madrid. 119-172.

GAMO PARRAS, Blanca (1998): La antigüedad tardía en la provincia de Albacete. Instituto de Estudios albacetenses "Don Juan Manuel" ser.l, no 107, Albacete.

GARCÍA MORENO, Luis A. (1975): El fin del reino visigodo de Toledo: decadencia y catástrofe : una contribución a su crítica. Madrid.

GARCÍA MORENO, Luis A. (1982): "Cecas visigodas y sistema económico", /I Reunió d'Arqueologia Paleocristiana Hispánica (Montserrat 1978). Barcelona. 333-346.

GARCÍA MORENO, Luis A. (1986): "El campesino hispanovisigodo entre bajos rendimientos y catástrofes naturales. Su incidencia demográfica". Los visigodos. Historia y civilización. Antigüedad y cristianismo III, (Murcia). 171-188.

GIL FARRÉS, Octavio (1955): "Algunos aspectos de la numismática visigoda. Consideraciones acerca del "tipo tercero" de Leovigildo", Numisma. 17. 25-71.

MARQUES GOMES, Mário; PEIXOTO CABRAL, João M. y RODRIGUES MARINHO, José (1995): Ensaios sobre historia monetària do monarquía visigoda, Porto.

GONZÁLEZ CARRASCO, L. (2006): "La numismática visigoda en la Comunidad de Madrid", Zona Arqueológica 8: Morín de Pablos (Ed.): La investigación arqueológica de la época visigoda en la Comunidad de Madrid, vol. III, cultura material. 815-819.

GURT I ESPARREGUERA J.M. (2007): “Complejos eclesiásticos no episcopales. Función y gestión" en Monasteria et Territorio. Elites, edilicia y territorio en el Mediterráneo medieval (siglos V-XI), ASLAEME-BAR, International Series 1720. Oxford. 203-232.

GUTIÉRREZ LLORET, Sonia (1999): "La ciudad en la antigüedad tardía en el Sureste de la provincia Carthaginiensis: la reviviscencia urbana en el marco del conflicto grecogótico", Acta Antiqua Complutensia I (Complutum y las ciudades hispanas en la Antigüedad Tardía, Alcalá de Henares, 1996). 101-128.

GUTIÉRREZ LLORET, Sonia (2000 a): "La identificación de Madinat lyyuh y su relación con la sede episcopal Elotana. Nuevas perspectivas sobre viejos problemas" Scripta in Honorem E.A.Llobregat. Alicante. 481-501.

GUTIÉRREZ LLORET, Sonia (2000 b): "El espacio doméstico altomedieval del Tolmo de Minateda (Hellín, Albacete), entre el ámbito urbano y el rural" Castrum 6. Maisons et espaces domestiques dans le monde Méditerranéen au Moyen Âge, (Erice-Trapani, 1993), CEFR 105/6-CCV 72, Rome - Madrid. 151-164. 
GUTIÉRREZ LLORET, Sonia (2000 c): "Algunas consideraciones sobre la cultura material de las épocas visigoda y emiral en el territorio de Tudmīr", Visigodos y Omeyas (Mérida 1999), Anejos de Archivo Español de Arqueología. XXIII. 95-116.

GUTIÉRREZ LLORET, Sonia (2002): “De espacio religioso a espacio profano: transformación del área urbana de la basílica del Tolmo de Minateda (Hellín, Albacete) en barrio islámico", II Congreso de Historia, vol. I Arqueología y Prehistoria. Instituto de Estudios Albacetenses "Don Juan Manuel". Excma Diputación de Albacete. Albacete. 307-316.

GUTIÉRREZ LLORET, Sonia (2008): "Madinnat Iyyuh y la destrucción del espacio urbano en la Alta Edad Media", en P. Cressier (ed.), Le château et la ville. Espaces et réseaux (Vle-XIle siècle). Castrum 8, Madrid. Casa de Velázquez École française de Rome. 199-222.

GUTIÉRREZ LLORET, Sonia (2011): "El Tolmo de Minateda en torno al 711", 711. Arqueología e Historia entre dos mundos, Zona arqueológica. 15, vol. I. 355-374.

GUTIÉRREZ LLORET, Sonia y ABAD CASAL, Lorenzo (2002): "Fortificaciones urbanas altomedievales del Tolmo de Minateda (Hellín, Albacete, España): el baluarte occidental", Mil Anos de Fortificaçôes na Península Ibérica e no Magreb (500-1500); Actas do Simpósio Internacional sobre Castelos, Lisboa, Ediçôes Colibri/ Cámara Municipal de Palmela. 133-143.

GUTIÉRREZ LLORET Sonia; ABAD CASAL, Lorenzo y GAMO PARRAS, Blanca (2004): "La iglesia visigoda de El Tolmo de Minateda (Hellín, Albacete)", Sacralidad y Arqueología. Thilo Ulbert zum 65 Geburtstag am Juni 2004 gewidmet (J. Ma. Blázquez y A. González Blanco, eds.) apud Antigüedad y Cristianismo. XXI. 137-70.

GUTIÉRREZ LLORET Sonia; ABAD CASAL, Lorenzo y GAMO PARRAS, Blanca (2005): "Eio, lyyuh y el Tolmo de Minateda (Hellín, Albacete): de sede episcopal a madîna islámica", VI Reunión de Arqueología Cristiana Hispánica (València, 2003). 345-368.

GUTIÉRREZ LLORET Sonia y CÁNOVAS GUILLÉN Pablo (2009): "Construyendo el siglo VII: arquitecturas y sistemas constructivos en el Tolmo de Minateda", en Caballero Zoreda Luis, Mateos Cruz Pedro y Utrero Agudo Ma Angeles (eds): El siglo VII frente al siglo VII : arquitectura : visigodos y Omeyas, 4, (Mérida 2006 ), Mérida : Instituto de Arqueología de Mérida. Anejos de Archivo Español de Arqueología. 51. 91-132.

GUTIÉRREZ LLORET, Sonia y CAÑAVATE CASTEJÓN, VÍctor (2010): "Casas y cosas: espacios y funcionalidad en las viviendas emirales del Tolmo de Minateda (Hellín, Albacete)", Cuadernos de Medinat al-Zahra 7. 123-148.

GUTIÉRREZ LLORET, Sonia y DOMÉNECH BELDA, Carolina (e.p): Coinage, Context and Social Space. The Early Medieval city of El Tolmo de Minateda (Hellín, Albacete, Spain), in Numismatica e Archeologia. Monete, stratigrafie e contesti. Dati a confronto, I Workshop Internazionale di Numismatica (WIN), Roma, septiembre 2011. Università di Roma-La Sapienza.
GUTIÉRREZ LLORET, Sonia y GRAU MIRA, Ignacio (2012): "El territorio tardoantiguo y altomedieval en el sureste de hispania: eio - iyyuh como caso de estudio", en L. Caballero, P. Mateos y T. Cordero Ruiz, T. (eds.): Visigodos y Omeyas: El territorio, Anejos de Archivo Español de Arqueología. LVI. 171-198.

GUTIÉRREZ LLORET, Sonia; GAMO PARRAS, Blanca y AMORÓS RUIZ, Victoria (2003): "Los contextos cerámicos altomedievales del Tolmo de Minateda y la cerámica altomedieval en el sureste de la Península Ibérica", Cerámicas tardorromanas y altomedievales en la Península Ibérica: ruptura y continuidad, II Simposio de Arqueología (Mérida 2001), Anejos de Archivo Español de Arqueología. 28. 119-168.

GUTIÉRREZ LLORET, Sonia y SARABIA BAUTISTA, Julia (2007): "El problema de la escultura decorativa visigoda en el sudeste a la luz del Tolmo de Minateda: distribución, tipologías funcionales y talleres", Escultura decorativa tardorromana y altomedieval en Hispania (15-17 diciembre 2004, Mérida). Anejos de Archivo Español de Arqueología. XLI. 299-341.

GUTIÉRREZ LLORET, Sonia y SARABIA BAUTISTA, Julia (2013): "The episcopal complex of Eio-El Tolmo de Minateda (Hellín, Albacete, Spain). Architecture and espatial organization. 7 th to 8 th AD", Hortus Artium Medievalium 19. 267-300.

GUTIÉRREZ LLORET, Sonia y SARABIA BAUTISTA, Julia (e.p): "L'episcopio del Tolmo de Minateda (Albacete, Spagna). Architettura e funzione degli ambientin tra la fine del VI e l'inizio dell'VIII secolo" en La Villa restaurata e i nuovi studi sull'edilizia residenziale tardoantica", Convegno internazionale Centro Interuniversitario di Studi sull'edilizia abitativa tardoantica nel Mediterraneo (CISEM), Piazza Armerina (7-10 novembre 2012)

HENDY, M. (1988): "From public to private: the western barbarian coinages as mirror of the disintegration of late roman state structures", Viator. 19. 29-78.

HILLGARTH, J.N. (1966): "Coins and chronicles: propaganda in sixth century Spain and the Byzantine background" Historia. 15. 483-508.

LECHUGA GALINDO, Manuel (2000): "Una aproximación a la circulación monetaria de época tardía en Cartagena: los hallazgos del teatro romano" V Reunió d'Arqueologia Cristiana Hispànica (Cartagena, 1998). Barcelona. 333349 .

LÓPEZ DE LA ORDEN, Ma Dolores y BLANCO JIMÉNEZ, Francisco J. (1999): "Avance sobre el hallazgo de dos tesorillos de monedas en el Teatro Romano de Cádiz", Il Congreso de Arqueología Peninsular (Zamora, 1996), t. IV. Alcalá. 283-287.

MAROT I SALSAS, Ma Teresa (1990): "Monedes vandals i bizantines a Pollentia”, Gaceta Numismática. 99. 29-33.

MAROT I SALSAS, Maa Teresa (1996): "Monedas vándalas y bizantinas procedentes de Santa Pola (Alicante)" Numisma. 237. 249-258. 
MAROT I SALSAS, Ma Teresa (1997): "Aproximación a la circulación monetaria en la Península Ibérica y las islas Baleares durante los siglos V y VI: La incidencia de las emisiones vándalas y bizantinas", Revue numismatique. 152. 157-190.

MAROT I SALSAS, Ma Teresa (2000): "El uso de la moneda en la antigüedad tardía", Los orígenes del cristianismo en Valencia y su entorno. Valencia. 273-278.

MAROT I SALSAS, Ma Teresa (2002): "La Península Ibérica en los siglos $V$ y VI: consideraciones sobre provisión, circulación y usos monetarios", X Congreso Nacional de Numismática (Albacete, 1998). Madrid. 71-96.

MAROT I SALSAS, Ma Teresa y LLORENS FORCADA, Ma Mar (1995): "La Punta de l'Illa de Cullera: aproximación a la circulación monetaria durante el siglo VI dC en el área valenciana". Anejos de Archivo Español de Arqueologia XIV. 253-260.

MAROT I SALSAS, Ma Teresa y LLORENS FORCADA, Ma Mar (1996): "La circulación monetaria en el siglo VI dC en la costa mediterránea: La Punta de l'Illa de Cullera (Valencia)", Revista d'Arqueologia de Ponent. 6. 151-180.

MAROT I SALSAS, Ma Teresa; LLORENS FORCADA, Ma Mary SALA SELLÉS, Feliciana (2000): "Contextos monetarios del siglo VI: las monedas procedentes de los vertederos del barrio de Benalúa (Alicante)" V Reunió d'Arqueologia Cristiana Hispànica, (Cartagena 1998), Barcelona. 507-517.

MARQUES DE FARIA, A. (1998): "On finds of Suevic and visigothic coins in the Iberian Peninsula and their interpretation", Problems of Medieval Coinage in the Iberian Area III. Santarem. 71-88.

MARTÍN VISO, Iñaki (2006): "Tributación y escenarios locales en el centro de la Península Ibérica: algunas hipótesis a partir del análisis de las pizarras "visigodas"”, Antiquité Tardive. 14. 263-290.

MARTÍN VISO, Iñaki (2008 a): "Tremisses y potentes en el nordeste de Lusitania (siglos VI-VII” Mélanges de la Casa de Velázquez. 38-1. 175-200.

MARTÍN VISO, Iñaki (2008 b): "La ordenación del territorio rural y la tributación en el suroeste de la meseta del Duero, siglos VI-VII", De Roma a los bárbaros: poder central y horizontes en la cuenca del Duero. Universidad de León. 227-261.

MARTÍN VISO, Iñaki (2011): "Circuits of power in a fragmented space: gold coinage in the Meseta del Duero (sixth-seventh centuries)" en Escalona, J. y Reynold, A. (eds.): Scale and scale change in the Early Midlle Ages. Exploring landscape, local society and the world beyond. Turnhout. 215-252.

MARTÍN VISO, Iñaki (2013): "Prácticas locales de la fiscalidad en el reino visigodo de Toledo", en X. Ballestín y E. Pastor (eds): Lo que vino de Oriente. Horizontes, praxis y dimensión material de los sistemas de dominación fiscal en Al-Andalus (sS. VII-IX). BAR, International Series 2525. Oxford. 72-85.
MATEOS CRUZ, Pedro; PIZZO, Antonio y PLIEGO VÁZQUEZ, Ruth (2005): "Un tesoro de tremises visigodos hallado en el llamado "foro provincial" de Augusta Emérita", Archivo Español de Arqueología. 78. 251-270.

MATEU I LLOPIS, Felipe 1941: "Las formulas y los símbolos cristianos en los tipos monetales visigodos" Analecta Sacra Tarraconensia, XIV. 75-98.

METCALF, D.M. (1988): "For what purposes were Suevic and Visigothic Tremisses used? The contribution of topographical analysis, illustrated by some comments on single finds from the Alentejo, and on the mint of Elvora" Problems of Medieval Coinage in the Iberian Area 3. 15-34.

METCALF, D.M. (1999): "Visigothic monetary history: The Facts, What facts?", The Visigoths. Studies in. Culture and Society. Leiden-Boston-Köln. 201-217.

MILES, G.C., 1952: The Coinage of the Visigoths of Spain. Leovigild to Achila II. New York.

ORLANDIS, José (1972-3): "Sobre el nivel de vida en la Hispania visigótica”, Anuario de Estudios Medievales. 8. 17-33.

ORLANDIS, José (1977): “La moneda”, Historia de España: la España Visigotica. Madrid. 199-203.

PALOL I SALELLAS, Pere de (1952): "El castro hispanovisigodo de Puig Rom (Rosas)". Informes y Memorias de la Comisaría General de Excavaciones Arqueológicas. 27. 163-182

PALOL I SALELLAS, Pere de (1986): "Las excavaciones de conjunto de El Bovalar, Serós (Segrià, Lleida) y el reino de Akhila”. Los visigodos. Historia y civilización. Antigüedad y Cristianismo III. Murcia. 513-525.

PALOL I SALELLAS, Pere de (dir.) (1999): Del romà al romànic. Història, art i cultura de la Tarraconense Mediterrània entre els segles IV i X. Enciclopèdia catalana. Barcelona.

PLIEGO VÁZQUEZ, Ruth (2009): La moneda visigoda, 2 vols. Universidad de Sevilla. Sevilla.

PLIEGO VÁZQUEZ, Ruth (2011): "La moneda en el ocaso del reino godo de Hispania", en 711 Arqueología e Historia entre dos mundos, Zona Arqueológica. 15. vol. 11. 321-337.

PLIEGO VÁZQUEZ, Ruth (2012): "La moneda visigoda: Anexo I", Homenaje al Prof. Dr. Manuel Bendala Galán. Spal. 21. 209-231.

RETAMERO I SERRALVO, Felix (1999): "El temps de les monedes. Concilis, porcs, collites i tremisses en época visigoda", Gaceta Numismática. 133. 69-76.

RETAMERO I SERRALVO, Felix (2001): "Panes et siliquae. Las condiciones de la producción de moneda en el Regnum Gothorum", Visigoti e Longobardi, Atti del seminario (Roma 1997). Firenze. 117-132. 
RETAMERO I SERRALVO, Felix (2011): "La moneda del Regnum Gothorum (ca. 575-714). una revisión del registro numismático", Between Taxation and Rent. Fiscal problems from Late Antiquity to Early Middle Ages. Entre el Impuesto y la Renta. Problemas de la fiscalidad tardoantigua y altomedieval, P. C. Díaz y I. Martín Viso (eds.). Bari. 2011. 189-220.

RODRÍGUEZ-PASCUA, M.A.; ABAD CASAL, L.; PÉREZLÓPEZ, R.; GAMO PARRA, B.; SILVA, P.G.; GARDUÑOMONROY, V.H.; GINER-ROBLES, J.L.; PERUCHA, M.A.; ISRADE-ALCÁNTARA, I.; BISCHOFF, J. y CALVO, J.P. (2013): "Roman, Visigothic and Islamic vidence of earthquakes recorded in the archaeological site of "El Tolmo de Minateda" (Prebetic Zone, southeast of Spain)", Cuaternario y Geomorfología. 27. 5-32.
SILLIĖRES, Pierre (1982): "Une grande route romaine menant à Carthagène: la voie Saltigi-Carthago Nova", Madridder Mitteilungen. 23. 247-257.

SILLIĖRES, Pierre (1990) : Les voies de communication de l'Hispanie méridionale. París.

VICO MONTEOLIVA, Jesús; CORES GORMENDIO,María Cruz y CORES URÍA, Gonzalo (2006): Corpus Nummorum Visigothorum. Ca.575-714 Leovigildus-Achila, Madrid.

VIGIL-ESCALERA GUIRADO, Alfonso (2011): "Formas de poblamiento rural en torno al 711: documentación arqueológica del centro peninsular", 711. Arqueología e Historia entre dos mundos, Zona arqueológica. 15, vol. I. 188-201. 